\title{
A Review of Tunable Acoustic Metamaterials
}

\author{
Shuang Chen ${ }^{1}$, Yuancheng Fan ${ }^{1} * \mathbb{C}^{\mathbb{D}}$, Quanhong Fu ${ }^{1}$, Hongjing $\mathrm{Wu}^{1}{ }^{\mathbb{D}}$, Yabin Jin ${ }^{2,3}$, \\ Jianbang Zheng ${ }^{1}$ and Fuli Zhang ${ }^{1, *}$ \\ 1 Key Laboratory of Space Applied Physics and Chemistry, Ministry of Education and Department of Applied \\ Physics, School of Science, Northwestern Polytechnical University, Xi'an 710129, China; \\ cs2016@mail.nwpu.edu.cn (S.C.); fuquanhong@nwpu.edu.cn (Q.F.); wuhongjing@mail.nwpu.edu.cn (H.W.); \\ zhengjianbang@nwpu.edu.cn (J.Z.) \\ 2 Institut de Mécanique et d'Ingénierie, CNRS-Université de Bordeaux, 33405 Talence, France; \\ yabin.jin@u-bordeaux.fr \\ 3 School of Aerospace Engineering and Applied Mechanics and Institute for Advanced Study, \\ Tongji University, Shanghai 200092, China \\ * Correspondence: phyfan@nwpu.edu.cn (Y.F.); fuli.zhang@nwpu.edu.cn (F.Z.)
}

Received: 5 July 2018; Accepted: 19 August 2018; Published: 28 August 2018

\begin{abstract}
Acoustic metamaterial science is an emerging field at the frontier of modern acoustics. It provides a prominent platform for acoustic wave control in subwavelength-sized metadevices or metasystems. However, most of the metamaterials can only work in a narrow frequency band once fabricated, which limits the practical application of acoustic metamaterials. This paper highlights some recent progress in tunable acoustic metamaterials based on various modulation techniques. Acoustic metamaterials have been designed to control the attenuation of acoustic waves, invisibility cloaking, and acoustic wavefront engineering, such as focusing via manipulating the acoustic impedance of metamaterials. The reviewed techniques are promising in extending the novel acoustics response into wider frequency bands, in that tunable acoustic metamaterials may be exploited for unusual applications compared to conventional acoustic devices.
\end{abstract}

Keywords: acoustic metamaterials; tunability; effective mass density; effective bulk modulus; Helmholtz resonator

\section{Introduction}

Metamaterials are rationally designed artificial structures with periodically or non-periodically arranged subwavelength elements [1-4], which exhibit unusual properties beyond natural occurring media [5]. The metamaterials have been widely investigated for guiding and controlling the flow of electromagnetic waves and acoustic waves in a supernatural manner since its discovery [6-14]. Novel wave manipulations such as the negative index, reversed Cherenkov radiation [15], and inverse Doppler effect [16] have been demonstrated experimentally. With such novel physical characteristics, the subwavelength metaatom-based metamaterial gives birth to the perfect lens, invisibility cloaks, and other new types of functional devices. As such, it provides new physical mechanisms in manipulating classical waves in comparison with traditional materials and devices. The features of metamaterials are determined to a great extent by the rationally designed metaatoms, instead of the intrinsic properties of natural materials [17-20]. Since the geometric parameters of metamaterials can be specifically optimized, desirable properties can be acquired by changing the topology and sizes [21-25]. Due to their ability to control wave-matter interactions [26-30], metamaterials have been proven to be an important concept for the development of functional materials [31-40].

Electromagnetic (EM) metamaterials have been intensively studied since the birth of metamaterials, and the research on EM metamaterials has achieved great progress [41-46]. As early 
as the 1960s, the concept of negative refraction was proposed. Sir John Pendry proposed a kind of composite made of periodic metal rods for realizing negative permittivity at a microwave frequency band in 1996 [1], and then another kind of structure constructed of resonant split rings was proposed to achieve the negative permeability in 1999 [2]. Based on these theoretical considerations, Smith et al. exquisitely designed and fabricated hybrid structures with periodic metal rods and resonant split rings. The existence of a negative index was directly proved through the observation of negative refraction $[3,47]$. Since then, metamaterials have attracted intensive studies, and various optical, terahertz, and microwave metamaterials have already been developed in the past decades [48,49].

Acoustic waves, which play important roles in our modern daily life, are similar to EM waves in their master equations. Since sound waves and electromagnetic waves have a large amount of analogical characteristics, the supernatural phenomena such as negative refraction [50], invisible cloak [51,52], and wavefront manipulation [53] also occur through specific designed acoustic composite structures, i.e., acoustic metamaterials (AMMs). AMMs are a new type of man-made structure that regulate acoustic behavior, resulting in negative effective mass densities and negative effective bulk modulus based on localized resonance mechanisms as well as extraordinary scattering properties [54].

For traditional acoustic materials, the insulation and absorption of low-frequency sound is confronted with great challenges due to the limitation of mass density law (which states that the acoustic transmission loss through a wall is proportional to the product of wall thickness, the mass density, and the sound frequency) [55,56]. Recent reports show that AMMs demonstrate an excellent performance of acoustic attenuation surpassing the traditional matter, especially at low frequency. In the study of AMMs, numerous attempts are concentrated on adjusting the density or the bulk modulus of the structures to manipulate the scattering of acoustic waves [57-60]. AMMs are considered as those complex material structures, rather than the sum of component parts, that are proposed and manufactured to modulate the propagation of acoustic waves in gases, liquids, and solids [61,62].

An acoustic band structure with periodic acoustic lattice was proposed in the last decades that has shown novel properties of sound propagation [63-72]. Although the AMM is composed of periodic structures, the working mechanism of AMM is locally resonant rather than the Bragg scattering in the earlier acoustic band gap material, which is called a phononic crystal (PC) [73-75]. Properties of AMMs can be described with homogenized parameters, the effective mass density, and the effective modulus [76,77]. For traditional composite materials, the effective mass density reflects the inertial characteristic of a material. For a compound containing two components, in general, the static mass density $\rho_{\text {eff }}$ can be modeled as the volume average of the density of the two components [78]:

$$
\rho_{\text {eff }}=\rho_{1} f+\rho_{2}(1-f)
$$

where $f$ means the volume percentage of component 1 , and $\rho_{1}$ and $\rho_{2}$ are the mass density of component 1 and 2, respectively. However, for an artificial composite material with local resonators, there will be a relative motion between the matrix and the resonators if the displacement between them is not synchronous and even inverse [79]. The effective mass of this system can be acquired by [80,81]:

$$
D_{e f f} V=M_{0}+\frac{m \omega_{0}^{2}}{\omega_{0}^{2}-\omega^{2}}
$$

where $D_{\text {eff }}$ is the effective density, $V$ is the total volume, $\omega_{0}$ is the resonant frequency, $\omega$ is the angular frequency of the time harmonic excitation, and $M_{0}$ and $m$ are the mass of the matrix and the solid components, respectively.

Therefore, the effective density of the whole structure could be negative at some frequencies The first locally resonant sonic material, which is the prototype of AMMs, was demonstrated by Liu et al. in 2000 [82]. The unit of phononic crystal-like material is made of a solid material core with relatively high density and a soft coating, as shown in Figure 1a. This AMM exhibits dipolar resonant modes at certain frequency ranges where the wavelengths in the bulk medium are at least two orders of the 
lattice parameter. According to Equation (2), its effective mass density is calculated to be negative, so that the propagating wave becomes an evanescent wave, and low-frequency band gaps appear in the transmission. The gaps of the AMMs can be ascribed to Bragg scattering and local resonance. The Bragg scattering occurs around the frequency where the periodic constant of the acoustic material is of the order of the acoustic wavelength. The band-folding rising from the Bragg scattering can lead to band gaps in which the acoustic waves cannot propagate. Negative dynamic mass will occur when the frequency is close to the resonant frequency of the crystal. The negative mass density is analogous with a mass-spring model in which the matrix can be regarded as a spring, and the core is similar to the mass [81].
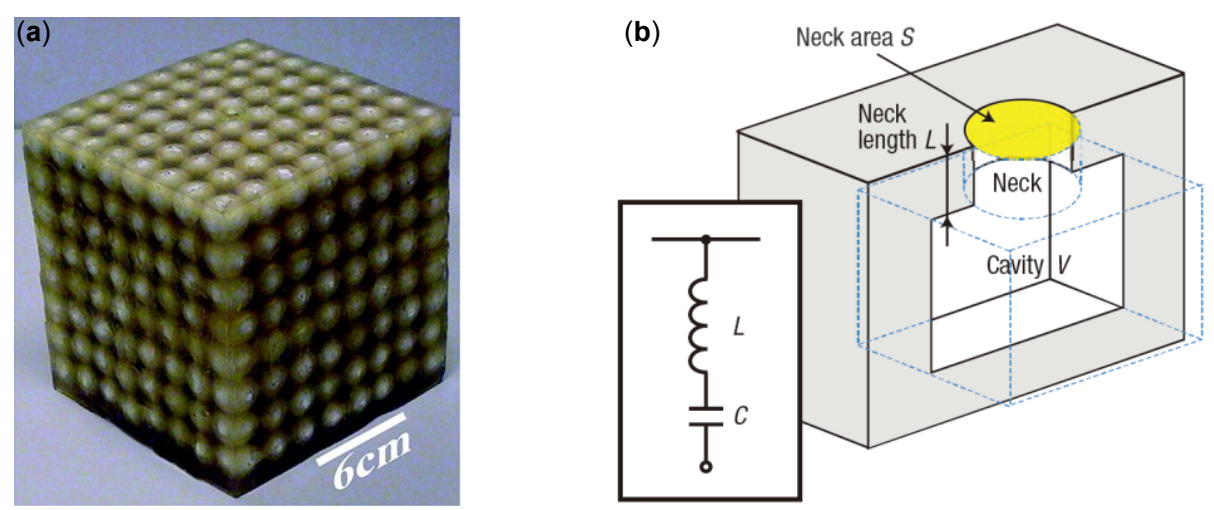

Figure 1. (a) Photograph of a local resonant acoustic structure. Adapted with permission from [82], The American Association for the Advancement of Science, 2000. (b) Schematic of periodical daisy-chained Helmholtz resonators. Adapted with permission from [83], Springer Nature, 2006.

Negative modulus can be designed by a class of AMMs consisting of an array of subwavelength-sized Helmholtz resonators, as shown in Figure 1b [83]. The system did not adopt the combination of different materials, but changed the geometry to limit the propagation of the acoustic wave in fluid [84]. The periodic shunted Helmholtz resonators can also be regarded as a simple mass-spring model [85]. Since the volume of the neck is much smaller than the volume of the cavity, it can be approximated that fluid in the neck is incompressible. Therefore, the fluid in the neck can be modeled as mass, while the fluid in the cavity can be considered a spring. In the framework of effective medium theory (EMT), the effective bulk modulus of fluid and solid composite structures $B_{\text {eff }}$ is [78]:

$$
\frac{1}{B_{e f f}}=\frac{1-f}{B_{1}}+\frac{f}{B_{2}}
$$

where $B_{1}$ and $B_{2}$ refer to the modulus of the matrix and solid components, respectively. When the damping of the system is negligible, the effective bulk modulus of a Helmholtz resonator can be written as [65]:

$$
\frac{1}{B_{e f f}}=\frac{1}{B}\left(1-\frac{\omega_{\mathrm{sh}}^{2}}{\omega^{2}}\right)
$$

where $B$ is the bulk modulus of air, $\omega_{s h}$ is the cutoff frequency of the side hole, and $\omega$ is the angular of the harmonic excitation. For the monopolar resonant mode of this AMM, the effective bulk modulus is found to be negative.

The monopolar and dipolar resonances of each scattering object are the key to realizing the negative effective modulus and effective mass density, respectively [50]. The negative effective properties indicate an out-of-phase wave response to the applied input; to be specific, it tends to move toward the left with the force to the right when the effective mass density is negative, while it expands with exerted pressure when the effective bulk modulus is negative [86]. When both situations occur simultaneously, a frequency range appeared in which propagation in the AMM is allowed; 
then, the acoustic structure is classified as a double negative acoustic metamaterial. In these negative composite structures, the effective wave velocity $V_{\text {eff }}$ is given by [87]:

$$
V_{e f f}=\sqrt{\frac{B_{e f f}}{D_{e f f}}}
$$

In Equation (5), when both negativities occur simultaneously, the terms within the square root are positive and the velocity is real. The acoustic wave is a transmission wave rather than an evanescent wave in single negative structures. Then, a pass band appears in the band structure, which is called a double negative acoustic metamaterial. A one-dimensional structure was first designed and demonstrated experimentally for double negative acoustic metamaterials [88]. The dipole resonance was regulated by the elastic membrane arranged periodically, and the monopolar response was provided through the side opening tube. Researchers found a double negative band at the low frequency limitation; the same configuration was employed for demonstrating the reverse Doppler shift in the double negative zone [68]. Later various attempts were exploited for tuning both the density and the bulk modulus for developing composite acoustic structures with tunable properties. For example, a classical design with double negativities was designed by Yong et al. [89], in which an array of glass bottles are attached to a plastic tube wall, and the membranes are also fixed among the resonators as well. These bottles operate as Helmholtz resonators with negative mass density, and the membranes convey collective acoustic oscillation that is similar to that in plasmonics to achieve negative mass density.

The manipulation of acoustic waves has been investigated intensively in last decades [90-93]. The development of AMMs provides a new platform for the manipulation of the propagation of acoustic waves, including the airborne acoustic wave [94-96], underwater acoustic wave [97-100], elastic wave [76,101,102], and surface acoustic wave [58]. The theoretical and experimental research of an acoustic cloak [103], acoustic rectification [53], acoustic lens [104,105], and near-zero index [106] have been carried out. Although a great deal of investigations have been reported, many studies mainly focused on passive metamaterials with constant material properties [107]. The acoustic properties of passive metamaterials are difficult to change once they are fabricated, resulting in a fixed and narrow working band. For the enhanced performances of AMMs, it is highly desirable to achieve tunable or reconfigurable AMMs in which the scattering characteristics of acoustic waves can be changed in real time to broaden and tune the regulation frequency bands for AMMs.

These fascinating properties can be achieved with active AMMs (AAMMs), which have been implemented by incorporating active mechanisms such as active components and reconfigurable structural parts in passive metamaterials. The working bands, as well as the characteristics of AAMMs, can be actively tuned for a far-reaching application potential in multifunctional applications [108-113]. In this short review, we will summarize the recent progress in the topic of tunable AMMs. The diverse manipulating manners of tunable AMMs are stated as well, including different modulation techniques with piezos, mechanic interactions, voltage, electromagnetic field, fluid filling, temperature, and angle varying. Decorated membrane resonators (DMRs) AMM with double negative parameters are expounded as well. At last, new classes of AMMs with tunable band gaps are reviewed.

\section{Piezoelectric Control of Acoustic Metamaterials}

According to the converse piezoelectric effect, the mechanical parameters of piezos (PZT) change under voltage, so emphatic research on the local resonant gap and the negative material properties of the AMM is significant to design a new AAMM. Since an active acoustic cloak consisting of an array of fluid cavities separated by piezoelectric boundaries was designed by Baz [107], lots of research combining PZT with AMM has been proposed [114-117]. A theoretical analysis of one-dimensional AMMs with piezoelectric boundaries has been discussed by Akl et al. [84]. In comparison to the equivalent transmission line theory, lumped parameter models can be employed to approach 
the acoustic response composite structures. For example, the electrical current, electric potential, the electrical capacitor, and electrical inductor are in analogy with the acoustic volume flow rate, acoustic pressure difference, the acoustic cavity compliance, and the acoustic mass.

Airoldi and Ruzzene demonstrated the experimental research on shunted piezos [118-120]. A beam is fixed with periodic shunted piezoelectric patches whose electrodes are connected to the Antoniou's circuit (shown in Figure $2 b$ ) because of its high value of inductance. The equivalent inductance of the circuit is $L=Z_{1} Z_{3} Z_{4} C_{1} / Z_{2}$, where $C_{1}$ is the capacitance of the piezoelectric patch. Then, the resonance frequency can be calculated with:

$$
f_{0}=1 / 2 \pi \sqrt{L C_{p}}
$$

where $C_{p}$ is the equivalent capacitance of this sample, and $f_{0}$ could be tuned by changing the value of $Z_{4}[119]$.
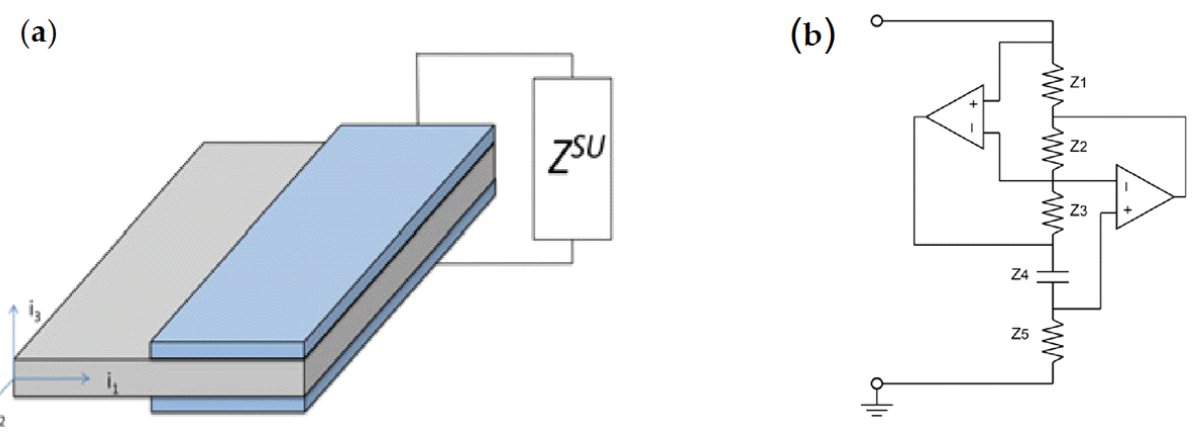

Figure 2. (a) A unit cell with shunting through an electrical impedance; (b) A circuit diagram of Antoniou's circuit. Reproduced under a Creative Commons CC BY 3.0 Licence [120] Copyright 2011, IOP Publishing.

Since the effective parameters can be tuned in real time by introducing piezoelectric patches into compound structures, AAMMs with tunable bands and resonant frequencies can be acquired consequently. Akl et al. proposed a series of schemes with acoustic fluid domains and piezoelectric subdomains [61,121-123]. A straight acoustic cavity with a rigid wall is coupled from both ends to bimorph diaphragms, as shown in Figure 3a. The periodical structure consists of an array of identical composite units that are fabricated by depositing PZT layers on both surfaces of the Brass disk. The composite cell is sensitive to the effect of actuated voltage, and the stiffness along the propagation path will be tuned. Meanwhile, these two bimorph diaphragms play different roles as sensor and actuator in adjusting the transmission of sound waves (Figure 3b). When an incident acoustic pressure is exerted on the cell, the sensing bimorph will measure the sound signal and submit it to the actuating bimorph by a feedback control circuit with a controller and amplifier. Then, the effective mass density of the cell could be tuned actively by changing the stiffness of the bimorphs via the power amplifier. The subsequent analysis and experimental results were demonstrated by this research group as well [122]. The sample was measured by being mounted on an impedance tube, and it showed homogenized dynamic properties over a frequency bandwidth approaching $3 \mathrm{kHz}$. In Figure 3c, the PZT layers operating as sensor and actuator can also be used in the sonic acoustic domain by bonding on both sides of a Brass plate [124].

Another AAMM is composed of a square of ultra-thin foil fixed by a rigid boundary; a pair of piezoelectric patches are attached to the center of the foil [55]. The finite element method and an impedance tube were used to numerically and experimentally study sound transmission behaviors, respectively. The sound transmission loss (STL) [125] can be calculated by:

$$
\mathrm{STL}=10 \log _{10}\left(W_{\text {in }} / W_{t r}\right)
$$


where $W_{i n}$ and $W_{t r}$ are the energy of incidence and transmission acoustic waves, respectively.

(a)

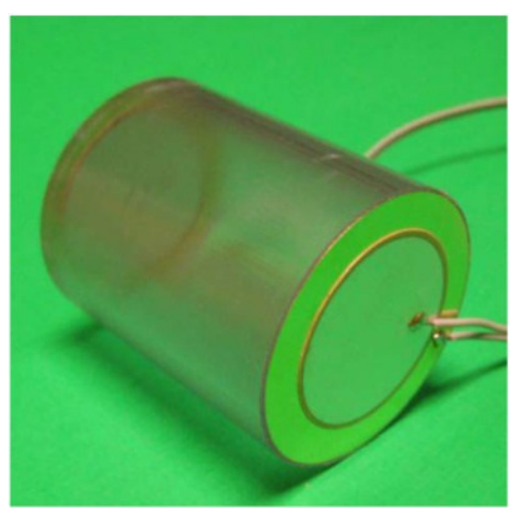

(c)

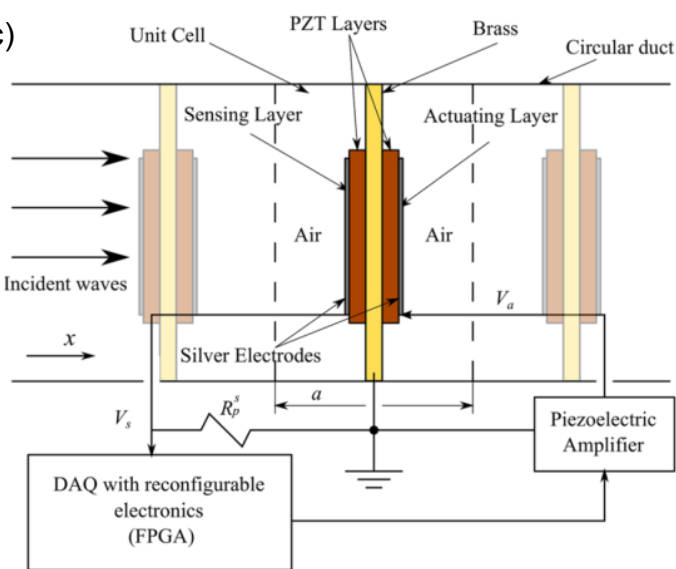

(b)

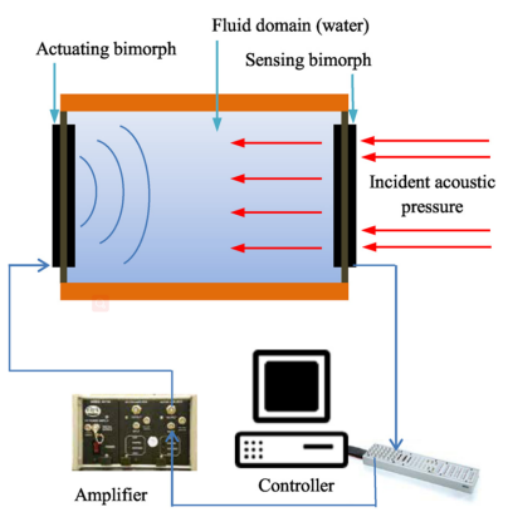

(d)

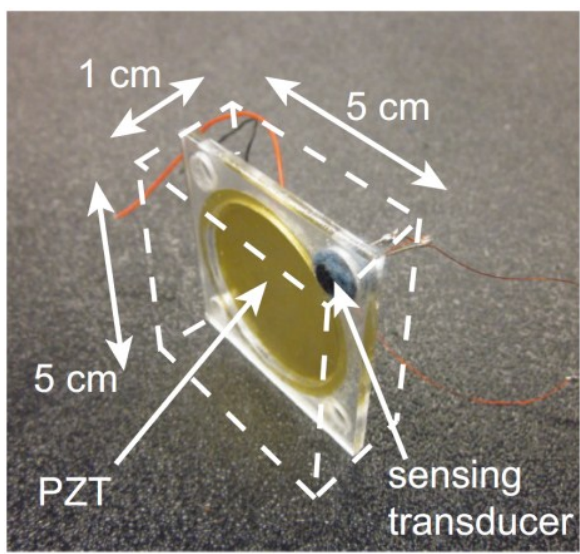

Figure 3. Schematic of (a) The active composite sample; (b) The operation mechanism of the proposed cell. Adapted with permission from [121], AIP Publishing, 2012. (c) The construction of the suggested one-dimensional (1D) acoustic metamaterial (AMM) with one unit cell of the material highlighted. Adapted with permission from [124], AIP Publishing, 2017. (d) The active composite sample. Adapted with permission from [126], APS, 2013.

According to Equation (6), the resonance can be controlled by the varying value of the equivalent inductor. Then, the STL properties can be modulated actively. Considering that the transmitted wave is a plane wave, the STL can be further expressed as [55]:

$$
\mathrm{STL}=10 \log _{10}\left(1+\left(\frac{\omega \rho_{\text {eff }}}{2 \rho_{0} c_{0}}\right)^{2}\right)
$$

From Equation (8), we can see that when the effective dynamic mass density $\rho_{\text {eff }}$ is approaching infinity near the resonant frequency, the STL peak will be observed. Similarly, a two-dimensional AMM consisting of a substrate with arrays of piezoelectric patches fixed on the both sides of the plate is proposed by Chen et al. [115], in which a locally resonant bandgap arises because the internal oscillators between shunting inductors and piezo-patches split the dispersion curves.

Bonding membranes with piezoelectric materials is a valid mean of controlling metamaterials dynamically.

DMRs and Helmholtz resonators are widely applied in achieving negative mass density and negative bulk modulus. Composite AMMs with double negativities are proposed to achieve new features beyond single negative characteristics. An AAMM with a hard core coated by PZT composite materials was designed by Jin et al. [127]. Negative mass density and elastic modulus occurs simultaneously by switching the electrical boundaries of the PZT material. The piezoelectric 
constant $e_{33}$ is confirmed to have a significant influence on the frequency range with an effective negative modulus. A feasible design on sound insulation was reported in a study by Liang et al. [128], in which acoustoelastic surface modes with double negativity behaviors were realized. The idea is to curve periodic slits into a perfect rigid screen and fill in the holes with elastic material. Similar to the Drude-like metamaterial, the transmittance gap of the sample could be changed to control surface waves by adjusting the inclusion, lattice constant, and scale of slits. Another example is illustrated by Rogelio et al. to show that the double negative properties of airborne sound transmission can be manipulated by simple scattering units without membranes [129]. The acoustic structure consists of arrays of cylindrical cavities embedded in a two-dimensional waveguide, and each scatterer is surrounded by anisotropic fluid-like metamaterials. It should be noted that the scatterers penetrate the upper surface of the waveguide. As the sound speed in scatterers is smaller than that in the background fluid, the wavelength in the shells is shorter than that of the background. When oscillator behavior occurs in the shells due to the acoustic pressure, a series of resonances could be induced consequently.

Most double negative AMMs are mainly designed by fastening elastic membranes in the intervals of an array of Helmholtz cavities, which manipulate the mass density and the bulk modulus, respectively. However, the control methods above are mutually independent, so the compressibility of the resonator changes only the modulus, and the deformation of the membrane alerts only the density [130]. Since piezoelectric plates could efficiently adjust both negative effective density and negative bulk modulus in certain frequency ranges, Popa et al. proposed a new method of adjusting these two parameters simultaneously [126], in which an electrode is fixed in a hole drilled in the plastic frame that is fabricated by felt fabric to attenuate the vibration, as shown in Figure $3 \mathrm{~d}$. When the vibrations transmit through the fabric frame directly, the coupling in the system will be restrained consequently, and the intracell instability will evidently decrease as well. Since the piezoelectric membrane is actuated actively and generates a strong resonance, the parameters of the unpowered unit are constants, while those of the powered unit vary within a large frequency range. Then, the sample can be dynamically controlled by exerting an external active system to achieve varying properties.

A very thin AMM slab similar to the above structure was designed by Popa et al. as well [131], in which the sample consisted of an array of membranes fastened between identical Helmholtz resonators to change its local acoustic response. The transmission characteristics of these units could be adjusted by the digital electronics. Moreover, the non-reciprocity and nonlinearity of AAMM is achieved [108]. The novel structure is a promising candidate to operate as a lens and a beam steering device at the same time. The digital manipulating manner renders a feasible way of actively controlling the AMM quantitatively and immediately.

\section{Mechanically Controlled Acoustic Metamaterials}

\subsection{Plunger Control}

In the AMMs with piezoelectric plates, multiple materials were used to construct the AMMs with novel properties [56]. The performance of an array of Helmholtz resonators with constant parameters has been studied extensively $[132,133]$. Since the traditional Helmholtz resonators are characterized by stationary responses and operate at fixed frequency ranges, their application is impractical in an automotive environment.

Then, the dynamic regulation of the designed composite structures is an urgent matter to control low frequency noise. Lee et al. designed tunable Helmholtz resonators manipulated by the mechanical method [130], in which an array of side tubes connected to the wall of a main duct are tuned by the terminal plungers, as shown in Figure 4a. With the procession or retreat of the plungers, the effective compressibility of air in the configuration will be changed accordingly. Local resonances occur around the eigenfrequencies and generate a varying compressibility from $-\infty$ to $+\infty$ continuously, as shown in Figure $4 \mathrm{~b}$. Then, the effective bulk modulus of this acoustic construction can be achieved from 
negative to positive. At the lower frequency edge of each period, the compressibility is negative, and the sound became evanescent, so a stop band occurs in this range. The side Helmholtz resonators model renders a feasible pattern to solve the gap problems and realize the wide-range tunability uninterrupted. The tunable mechanism is suitable for adjusting the resonant-cavity type AMMs by changing the volume of fluid inside. However, there are still two problems with the control strategy. The tubes distance $d$ only affects the width of the resonance; it cannot change the period of effective compressibility $\beta_{r}$. As the mechanical method is a passive way to adjust the transmission spectrum, the accuracy of the regulation is limited. Then, a feedback circuit can be used in this equipment to control the displacement of the plungers quantitatively.

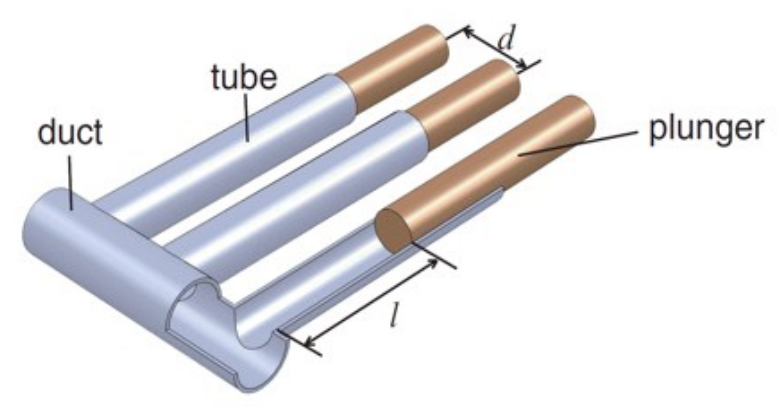

(a)

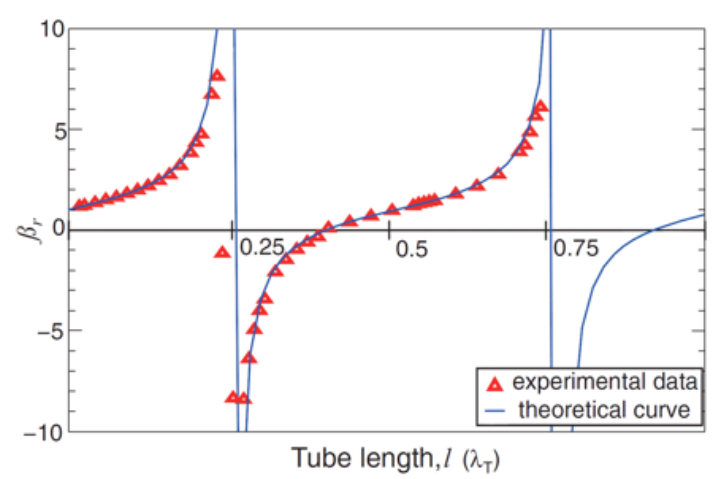

(b)

Figure 4. (a) AMM exhibits continuously tunable compressibility; (b) Theoretical curves and the experimental data for the effective compressibility $\beta_{r}$ of the duct as a function of the tube length $l$. Adapted with permission from [130], APS, 2012.

\subsection{Pressurized Air Control}

The membrane-type AMM with negative dynamic mass and a negative bulk modulus is an important kind artificial compound structure that can effectively absorb or reflect acoustic waves [56,97,134-139]. The structures consisting of DMRs have been explored intensively for surpassing the acoustic mass law. The DMR is composed of a tensioned elastic membrane whose boundary is fixed on a solid ring, and a platelet is pasted to the center of the membrane. The effective density $D_{\text {eff }}$ of the DMR could be calculated with $D_{\text {eff }}=\left\langle\sigma_{z z}\right\rangle /\left\langle a_{z}\right\rangle$, where $\sigma_{z z}$ and $a_{z}$ are the stress and acceleration normal to the membrane plane at rest, respectively [136]. By properly designing the negative effective mass density, the DMRs show a distinct advantage related to increasing sound insulation at low frequencies [56,140].

The transmission properties in the low-frequency range largely rely on its first two eigenmodes. Transmittance peaks arise at resonant frequencies, and transmittance dips occur at anti-resonance frequencies, respectively [141]. As a result, the resonant frequencies can be altered by adjusting the structure parameters of the configuration [142]. Super absorbers for low-frequency have been demonstrated by Mei et al. [143], in which thin elastic films decorated with designed patterns of rigid platelets effectively reduce the sound transmission. An active membrane-type metamaterial with centralized actuation is shown in Figure 5a [137], in which two vertically stacked DMRs are mounted onto a frame, and the whole configuration needs to be airtight. When an external source of pressurized air is exerted to alter the static pressure in the cabin by channels inside the frame, large nonlinear deformation could be acquired, as shown in Figure 5b. Hence, the eigenmodes and the transmission property of the sample will be changed. The peak of the STL curve shifts to a higher frequency with the increase of pressure difference $\beta_{0}$ (Figure $5 c$ ). 
(a)

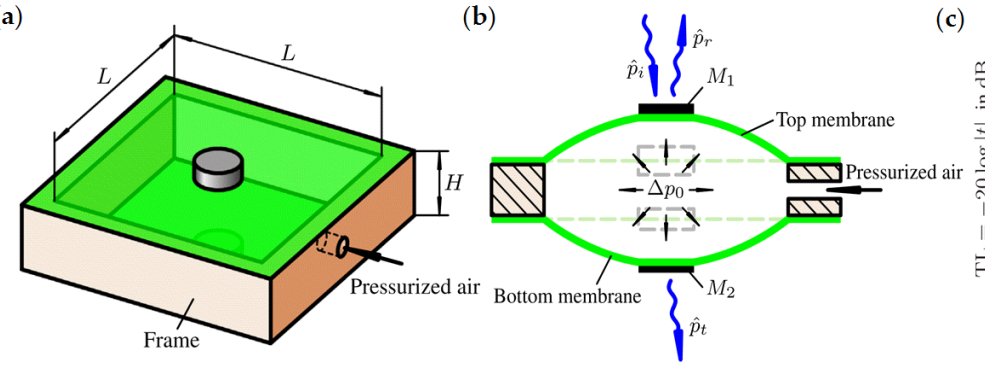

c)

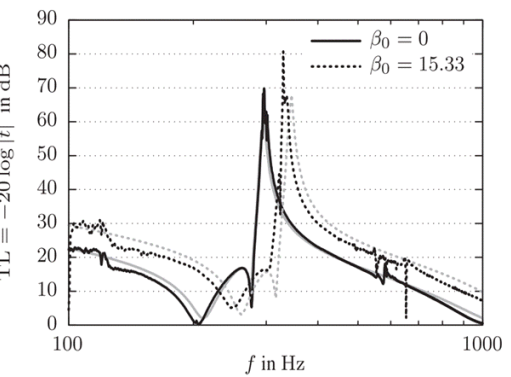

Figure 5. A unit cell of the proposed active AMMs (AAMM) with an inflatable double membrane AMM element. (a) Isometric view of the square AAMM unit cell; (b) Cross-sectional view through the AAMM unit cell; (c) Experimental and theoretical normal sound transmission loss (STL) for the double AMM at two different inflation pressure differences $\beta_{0}$. Adapted with permission from [137], Elsevier, 2016.

\subsection{Mechanical Deformation Control}

An adaptive AMM whose transmission properties are adjusted by mechanical deformation is proposed by Wang et al. [144]. Comparing with DMRs, the elastic membranes around the plate are replaced by flexible beams in this structure, as shown in Figure 6a. The black regions in the picture indicate voids in the structure. When a compressive strain $\varepsilon$ is exerted in the out-of-plane direction, the beams will deform (Figure 6b). Experimentally measured transmittance in a sample with $6 \times$ 3 unit cells at different applied prestrains is shown in Figure 6c. The resonant frequency of the sample changes with the varying strain consequently. Furthermore, this class of configurations can also be used as an acoustic switch.
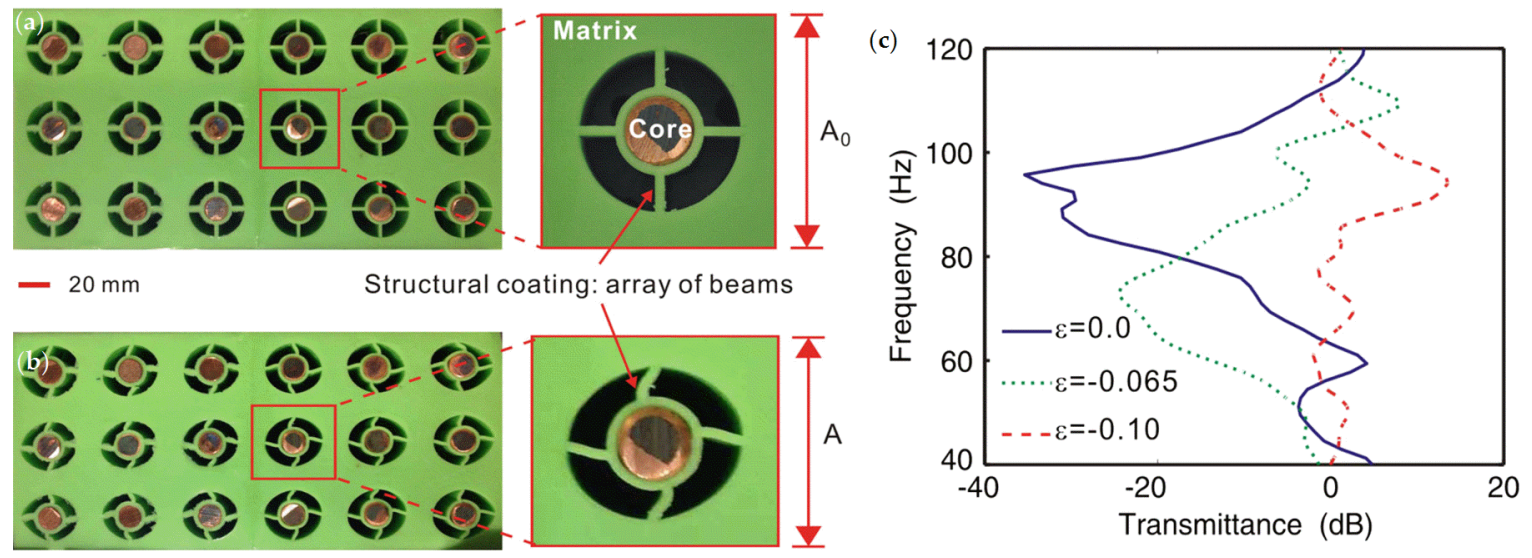

Figure 6. Tunable acoustic metamaterial: (a) Undeformed configuration comprises resonating units dispersed into an elastomeric matrix; (b) Deformation of the structure with a compressive strain in the vertical direction; (c) Experimental transmittance of the sample with different prestrains. Adapted with permission from [144], APS, 2014.

\section{Active Control with Electric and Magnetic Biasing}

\subsection{Active Control of Membrane-Type Acoustic Metamaterials by Electrode}

Another AAMM consisting of hollow cylindrical resonators is controlled by an external electric field to achieve negative effective density and tunable transmission coefficient [141]. This AMM is fabricated by a DMR as the bottom and a mesh structure as its top, as shown in Figure 7. The disk is coated with a layer of gold that can be regarded as a platelet electrode. The mesh structure is also coated with gold film to become a fishnet electrode. Therefore, both of them will operate as the 
electrodes of a plate capacitor when direct current (DC)/alternating current (AC) voltage is exerted between the mesh structure and the central disk. However, theories of the modulation by DC and AC voltage are quite different, because DC voltage exerts a force on the unit, but AC voltage offers a vibration source.

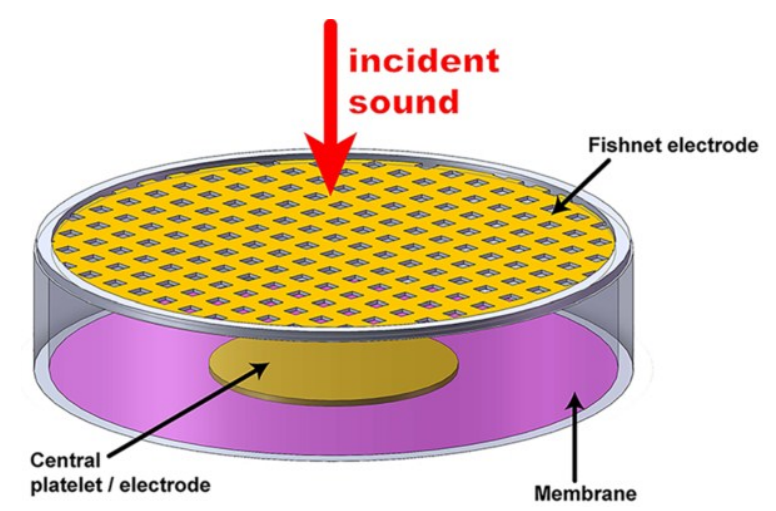

Figure 7. Schematic of the decorated membrane resonators (DMR) sample. Adapted with permission from [141], AIP Publishing, 2015.

\subsection{Active Control of Composite Acoustic Metamaterials by Electromagnets}

Electromagnets are another promising candidate for designing AAMM because of their tunable properties by voltage. A spatial sound modulator based on an active acoustic metasurface is designed and realized by Ma et al. [145]. As shown in Figure 8, the mode of membrane can be electrically switched from "ON" to "OFF", two states of the modulators. Switching is achieved by switching the DC voltage across the electromagnet.

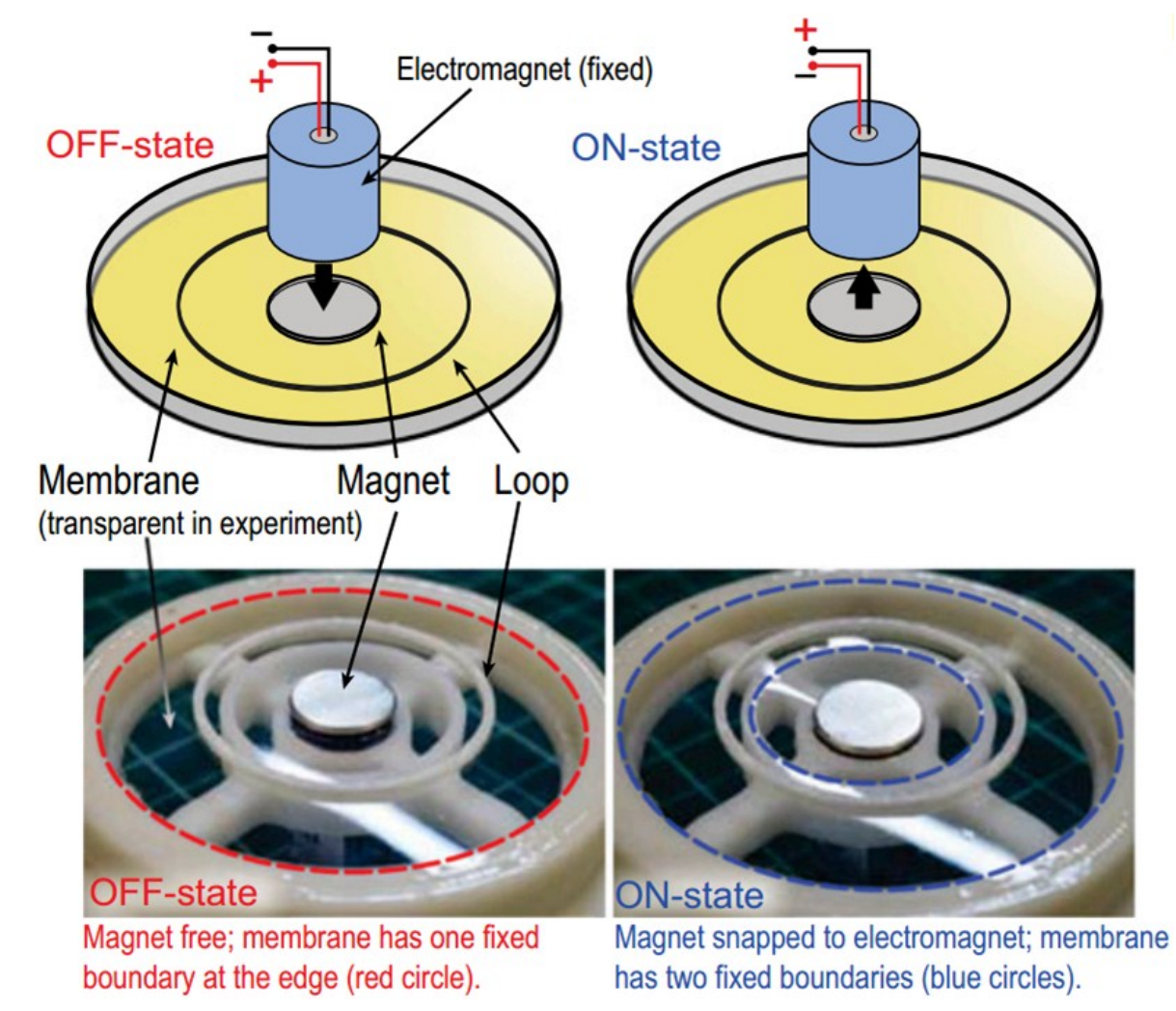

Figure 8. The unit cell design of the structure. Reproduced under a Attribution-Non-Commercial-No Derivatives 4.0 License [145] Copyright 2018, PNAS. 
Composite AMMs, coupling the characteristics of negative mass density and a negative bulk modulus, directly affect the speed of sound in many continuous domains. Chen et al. designed a double negative AMM manipulated by electromagnets [146]. They fabricated a periodical array of flexible membranes fastened on a main duct and an array of side holes drilled into the duct wall, as shown in Figure 9a. The membranes offer negative mass density with the acoustic waves transmitting (Figure 9c). Meanwhile, the holes evenly distributed among the membranes generate a negative bulk modulus. Electromagnets are applied to transform the membranes and change the interior tension when DC voltage is exerted. Different DC voltages could lead to varying transmission spectra, and a double negative pass band will form at their resonant frequencies (Figure 9b).

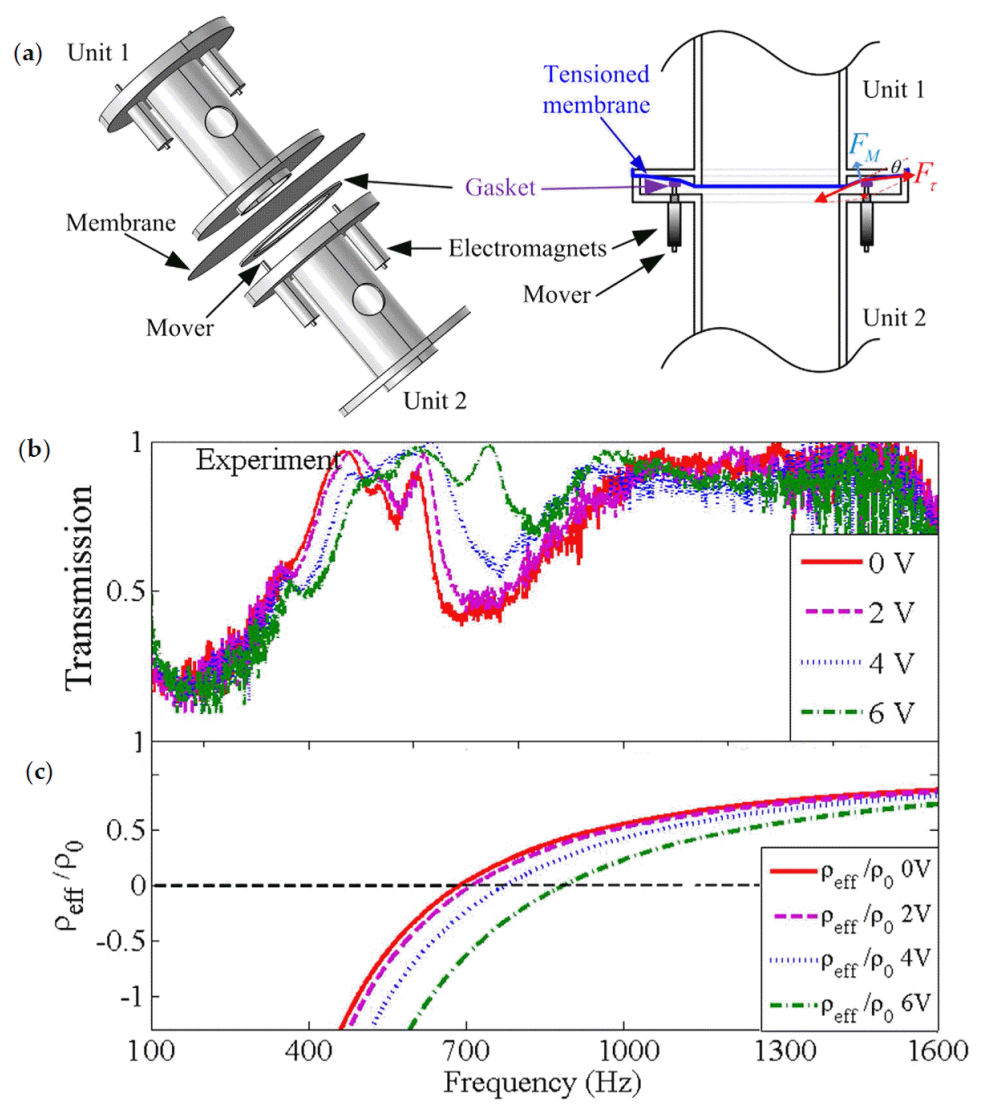

Figure 9. (a) Schematic drawing of the special structure for controlling and adjusting the effective stiffness of the membranes with electromagnets; (b) Experimental transmissions; and (c) Simulated equivalent density of the tunable double-negative metamaterials under different driving voltages supplied to the electromagnets. Reproduced under a Creative Commons Attribution 4.0 International License [146] Copyright 2016, Nature Publishing Group.

\section{Tunable Acoustic Metamaterials Based on Other Mechanisms}

Except for the piezoelectric, mechanical, electric, and magnetic control methods, some new mechanisms have been introduced in realizing tunabilities in acoustic metamaterials.

\subsection{Active Acoustic Metamaterials Biased with Magnetic Fields}

Research on actively tunable metamaterials based on elastic membranes has gained attention recently due to the negative mass density that can be achieved by membrane-type metamaterials [146]. The structural characteristics of the magnetorheological elastomer can be changed significantly by the external uniform magnetic field [147], the elastomers with ferroferric oxide $\left(\mathrm{Fe}_{3} \mathrm{O}_{4}\right)$ particles embedded in silicon rubber have great potential to modulate the local resonant band gaps or the Bragg 
scattering characteristics of AMMs. One of the samples is fabricated by $\mathrm{Xu}$ et al. [148], in which the magnetorheological elastic membrane is fixed by a non-magnetic metal tube, and the propagation properties in terms of the structure are achieved experimentally (Figure 10a). The magnetic field surrounding the sample can be decomposed into the identical radial portion and the gradient axial portion. The distribution of the axial magnetic field gradient is shown in Figure 10b; then, the experimental transmission loss and effective mass density spectrums are shown in Figure 10c, $d$ as well. With the location moving to the edge of the magnet, the axial magnetic field gradient increases, and the resonant frequency shifts to a higher frequency gradually at the zero-density point. It should be noted that the properties of this configuration are insensitive to the uniform magnetic field.

(a)

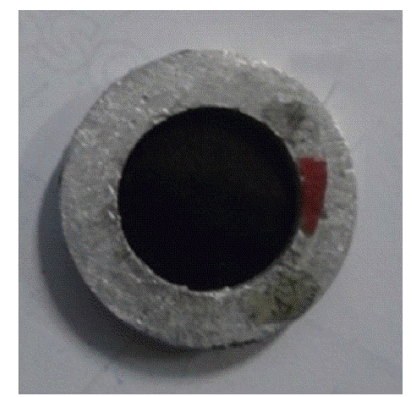

(b)

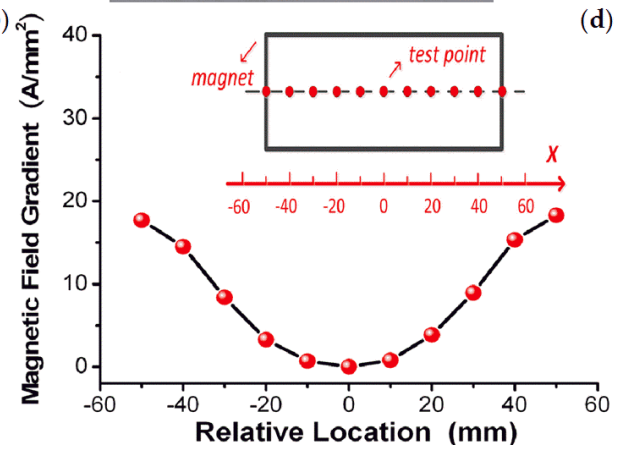

(c)

d)
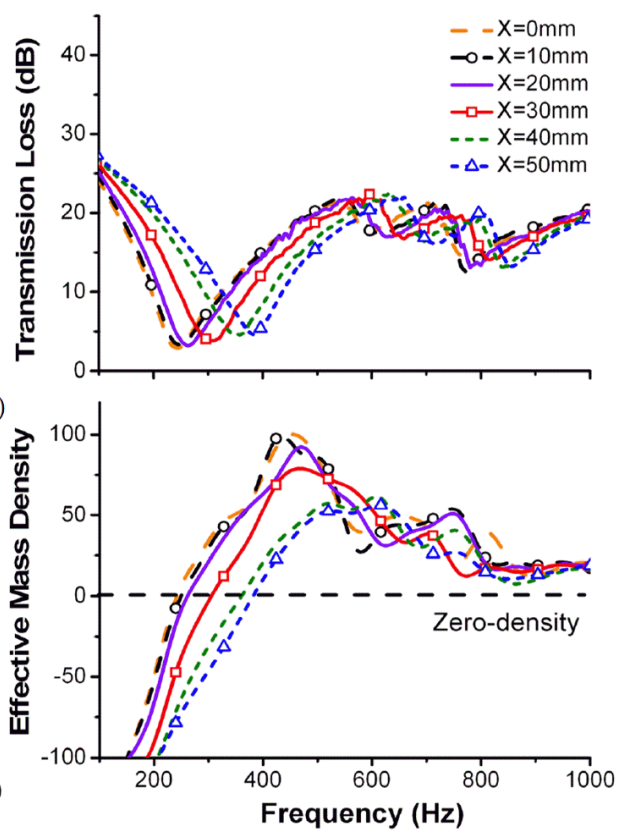

Figure 10. Tunable AMMs with varying magnetic field gradient. (a) Schematic front view of the membrane structure (the elastic membrane fabricated with magnetorheological elastomers is fixed by the support frame); (b) The magnetic field gradient varies along the axial direction. Inset: The schematic of test points; (c) The measured STL; and (d) Effective mass density spectra in different gradient magnetic fields. Adapted with permission from [148], AIP Publishing, 2014.

Another membrane-type sound absorber with magnetic negative stiffness is demonstrated using a viscoelastic-coated membrane with a light iron plate fixed on its center, and the membrane is fastened on the edge of a container as its top [149]. A cylindrical magnet is assembled on the bottom of the container and directly under the plate. The absorption spectrum could be tuned by changing the specific acoustic resistance of the membrane or the total stiffness of the absorber. On the basis of this configuration, actively controlled AMM can be fabricated by replacing the magnet by an electromagnet.

\subsection{Fluid-Filled Acoustic Metamaterial}

Unlike the extensively studied technique to achieve actively controlled AMMs by changing the tension of the membrane and reforming the compressibility of fluid in the cavities, some new types of manipulating method have also been proposed theoretically and implemented experimentally. Jin et al. proposed a novel plate with hollow pillars with existing whispering-gallery modes (WGMs) [75]. By tuning the inner radius of the pillar, these modes can merge inside both Bragg and low-frequency gaps, which can be used for phononic crystal and AMM applications. Filling the hollow parts with a fluid gives rise to new localized modes, which depend on the physical properties and height of the fluid. Thus, these modes can be actively controlled for the purpose of multichannel multiplexing [150]. 
Water and mercury are filled in the hollow, respectively, in the lab (Figure 11b). The upper end of the vertical bar is in the frequency of a WGM when the inner hole is empty, and the lower end is in the frequency when the inner hole is entirely filled with liquid. The upper frequency range that is limited by two horizontal cyan lines is the Bragg band gap, and the lower one is the low-frequency band gap. When the plate's hollow pillars are connected by thin bars, the Bragg band gap can be tuned to be much wider and extend to a subwavelength region, and the low-frequency gap can be shifted to an extremely low frequency [151].
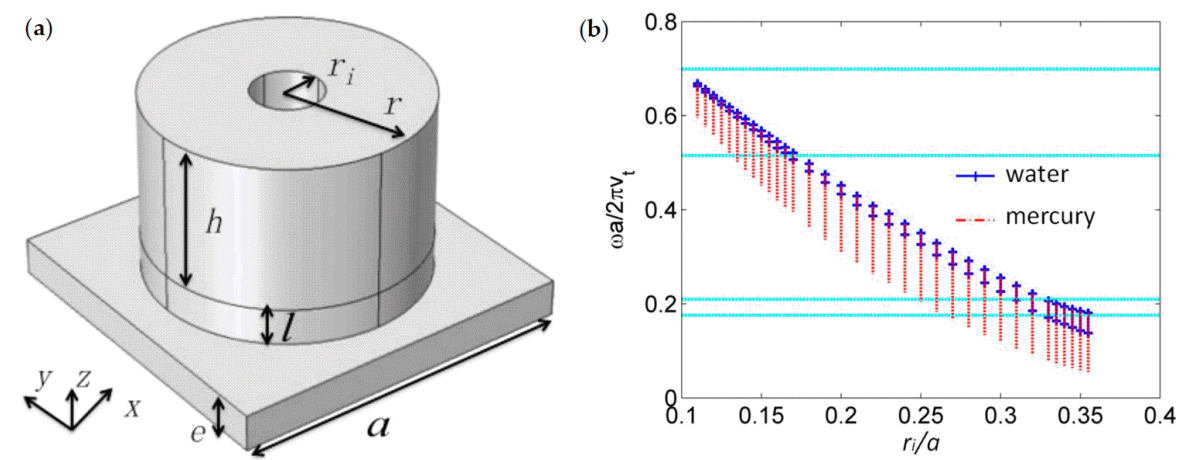

Figure 11. (a) Schematic view of a unit cell; (b) Varied range of whispering-gallery modes' (WGMs) frequency crossing from Bragg band gap to low-frequency band gap when the holes are respectively empty or fully filled with the liquid: water (blue dotted lines) and mercury (red dotted lines), corresponding to increasing inner radius. Reproduced under a Creative Commons Attribution 4.0 International License [150] Copyright 2016, MDPI.

\subsection{Temperature-Controlled Acoustic Metamaterials}

The intensive research on the influence of the fluid temperature on the features of sonic resonators is significant to achieve multiple functions such as phase modulation and acoustic wave transmission control. It is well known that the properties of a fluid are largely dependent upon its temperature. On the other hand, attaching side Helmholtz resonators to duct walls is a feasible way to attenuate the acoustic energy in narrow ranges around the resonant frequencies [84]. Then, a one-dimensional composite metamaterial is proposed by Xia et al. [152], in which a rigid wall acoustic duct is connected with an array of Helmholtz resonators and filled with water to realize sound insulation, as shown in Figure 12a. The sensitive shifts of the structure properties with frequencies in different temperatures are described in Figure 12b,c as well. Simultaneously, a negative effective bulk modulus is achieved near the resonant frequency. The properties of AMMs changed by the temperatures of internal fluid render a new method to modulate the transmission of sound effectively, but the manipulation of altering temperature rapidly and accurately is an urgent problem to be solved.

\subsection{Lossy Acoustic Metasurfaces with Tunable Asymmetric Transmission}

Asymmetric acoustic wave propagation is a new research direction to manipulate the wavefront of transmission and reflection $[153,154]$. The sample comprising an array of lossy gradient-index metasurfaces (GIM) is shown in Figure 13a, and every unit is fabricated by four arranged Helmholtz resonators. The transmission properties of the units can be adjusted by changing the structure parameters of the cavities. Experimental configuration is installed in an acoustic field, and $\theta$ means the rotation angle of the sample deviated from the initial direction. The energy contrast in Figure 13b indicates that there is a large asymmetry occurring in a specific incidence angular range. The symmetry property in a large angle region is caused by the impedance mismatch of the positive direction [155]. With an actuating force controlled by the external circuit, active tunable transmission properties could be achieved by changing the rotation angel of the GIM. In addition, the phase of the above units can 
be tuned from 0 to $2 \pi$ with the transmittance approximating to 1 , which makes the unit a promising candidate to twist acoustics.

(a)

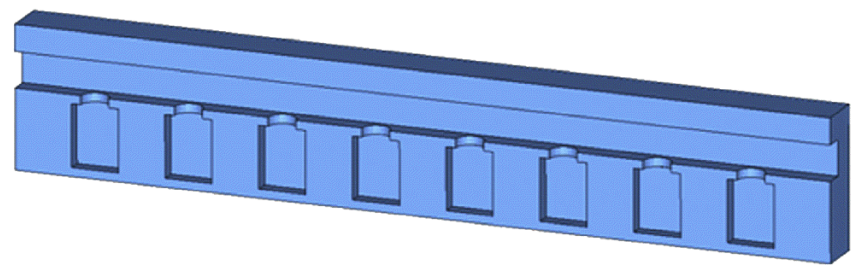

(b)
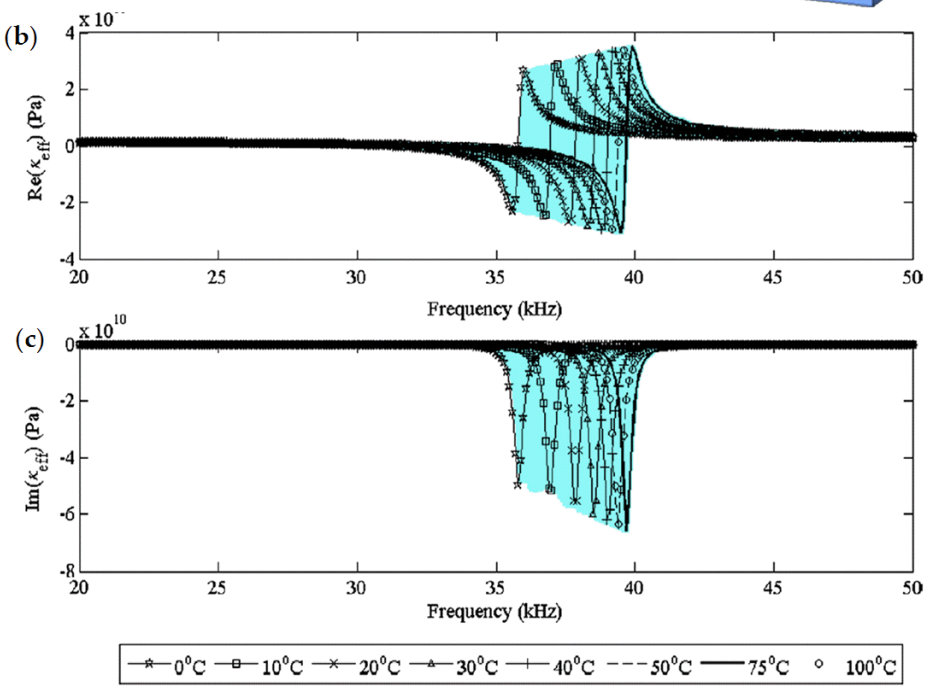

Figure 12. (a) A structured AMM consisting of an acoustic duct and periodic Helmholtz resonators; (b) The variation of the real part of the effective bulk modulus related to the temperature of water; (c) The variation of the imaginary part of the effective bulk modulus related to the temperature of water. Adapted with permission from [152] Elsevier, 2016.

(a)

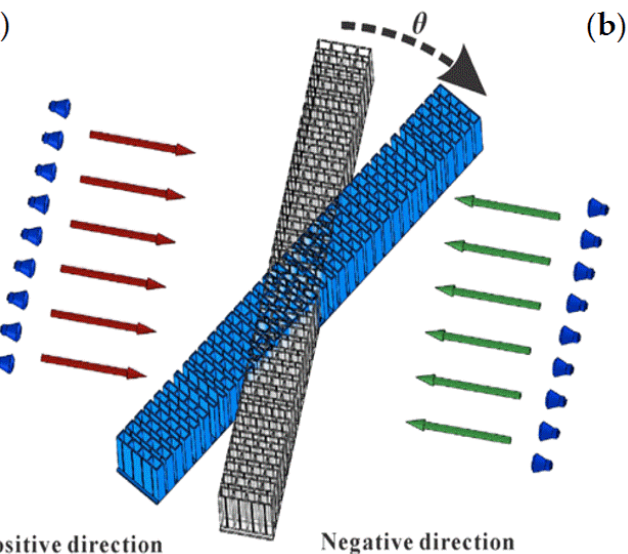

(b)

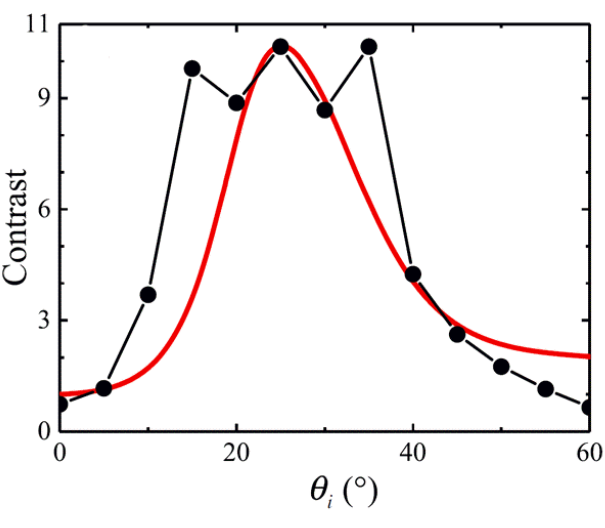

Figure 13. (a) The experiment setup of the fabricated prototype. The left (right) incidence corresponds to the positive (negative) direction case; (b) Energy contrast with different angles of incidence at $3430 \mathrm{~Hz}$ (red curve, simulation; black circles, measurement). Adapted with permission from [153], APS, 2017.

\section{Conclusions}

Manipulating acoustic waves with metamaterials and/or metasurfaces is helpful in realizing subwavelength acoustic devices and systems. However, the narrow working band of most of the fabricated metamaterials due to the local resonant nature of acoustic metamaterials may limit 
their practical application. In this review, we provide a survey of the recently developed tunable acoustic metamaterials based on various modulation techniques, including acoustic metamaterials with piezoelectric materials, mechanically controllable components, and with electric and magnetic biasing. Such active AMMs are promising candidates in many applications, including the attenuation of acoustic waves, invisibility cloaking, and acoustic wavefront engineering such as focusing. It is worth noting that intensive attempts on tunable AMMs have been proposed to actively modulate sound transmission/reflection in sonic, infrasonic, and ultrasonic fields. These studies are merely focused on theoretical and numerical modeling, as well as experimental demonstration; there is still a long way to go in the practical application of AAMMs.

Author Contributions: Y.F. and F.Z. conceived the review; S.C., Y.F., Y.J. and F.Z. wrote the manuscript. S.C., Y.F., Q.F, H.W., Y.J., J.Z. and F.Z. contributed in review of the manuscript.

Funding: This research was funded by the National Natural Science Foundation of China (No. 61771402, 61505164, 11674266, 11372248), the Natural Science Basic Research Plan in Shaanxi Province of China (No. 2018JM6024, 2017JM6094, 2017JQ5116), the Science and Technology Plan of Shenzhen City (JCYJ20170817162221169), the Hong Kong Scholars Program (XJ2017006), the Fundamental Research Funds for the Central Universities (No. 3102018jgc008, 3102017zy033, 3102018zy045), and the start-up fund from Tongji University.

Conflicts of Interest: The authors declare no conflict of interest.

\section{References}

1. Pendry, J.B.; Holden, A.J.; Stewart, W.J.; Youngs, I. Extremely low frequency plasmons in metallic mesostructures. Phys. Rev. Lett. 1996, 76, 4773-4776. [CrossRef] [PubMed]

2. Pendry, J.B.; Holden, A.J.; Robbins, D.J.; Stewart, W.J. Magnetism from conductors and enhanced nonlinear phenomena. IEEE. Trans. Microw. Theory Tech. 1999, 47, 2075-2084. [CrossRef]

3. Shelby, R.A.; Smith, D.R.; Schultz, S. Experimental verification of a negative index of refraction. Science 2001, 292, 77-79. [CrossRef] [PubMed]

4. Fleury, R.; Sounas, D.; Alù, A. An invisible acoustic sensor based on parity-time symmetry. Nat. Commun. 2015, 6, 5905. [CrossRef] [PubMed]

5. Ma, G.; Sheng, P. Acoustic metamaterials: From local resonances to broad horizons. Sci. Adv. 2016, 2, e1501595. [CrossRef] [PubMed]

6. Qin, F.; Ding, L.; Zhang, L.; Monticone, F.; Chan, C.C.; Deng, J.; Mei, S.; Li, Y.; Teng, J.; Hong, M. Hybrid bilayer plasmonic metasurface efficiently manipulates visible light. Sci. Adv. 2016, 2, e1501168. [CrossRef] [PubMed]

7. Pang, Y.; Wang, J.; Cheng, Q.; Xia, S.; Zhou, X.Y.; Xu, Z.; Cui, T.J.; Qu, S. Thermally tunable water-substrate broadband metamaterial absorbers. Appl. Phys. Lett. 2017, 110, 104103. [CrossRef]

8. Cui, T.J.; Liu, S.; Zhang, L. Information metamaterials and metasurfaces. J. Mater. Chem. C 2017, 5, $3644-3668$. [CrossRef]

9. Wang, Z.; Jing, L.; Yao, K.; Yang, Y.; Zheng, B.; Soukoulis, C.M.; Chen, H.; Liu, Y. Origami-Based Reconfigurable Metamaterials for Tunable Chirality. Adv. Mater. 2017, 29, 1700412. [CrossRef] [PubMed]

10. Wang, X.; Chen, H.; Liu, H.; Xu, L.; Sheng, C.; Zhu, S. Self-Focusing and the Talbot Effect in Conformal Transformation Optics. Phys. Rev. Lett. 2017, 119, 033902. [CrossRef] [PubMed]

11. Wang, Q.; Xiao, M.; Liu, H.; Zhu, S.; Chan, C.T. Optical Interface States Protected by Synthetic Weyl Points. Phys. Rev. X 2017, 7, 031032. [CrossRef]

12. Fan, Y.; Wei, Z.; Li, H.; Chen, H.; Soukoulis, C.M. Low-loss and high-Q planar metamaterial with toroidal moment. Phys. Rev. B Condens. Matter 2013, 87, 115417. [CrossRef]

13. Liu, Z.; Du, S.; Cui, A.; Li, Z.; Fan, Y.; Chen, S.; Li, W.; Li, J.; Gu, C. High-Quality-Factor Mid-Infrared Toroidal Excitation in Folded 3D Metamaterials. Adv. Mater. 2017, 29, 1606298. [CrossRef] [PubMed]

14. Zhu, W.; Yang, R.; Fan, Y.; Fu, Q.; Wu, H.; Zhang, P.; Shen, N.H.; Zhang, F. Controlling optical polarization conversion with Ge2Sb2Te5-based phase-change dielectric metamaterials. Nanoscale 2018, 10, 12054-12061. [CrossRef] [PubMed]

15. Xi, S.; Chen, H.; Jiang, T.; Ran, L.; Huangfu, J.; Wu, B.I.; Kong, J.A.; Chen, M. Experimental verification of reversed Cherenkov radiation in left-handed metamaterial. Phys. Rev. Lett. 2009, 103, 194801. [CrossRef] [PubMed] 
16. Chen, J.; Wang, Y.; Jia, B.; Geng, T.; Li, X.; Feng, L.; Qian, W.; Liang, B.; Zhang, X.; Gu, M. Observation of the inverse Doppler effect in negative-index materials at optical frequencies. Nat. Photonics 2011, 5, $239-245$. [CrossRef]

17. Schurig, D.; Mock, J.J.; Justice, B.J.; Cummer, S.A.; Pendry, J.B.; Starr, A.F.; Smith, D.R. Metamaterial electromagnetic cloak at microwave frequencies. Science 2006, 314, 977-980. [CrossRef] [PubMed]

18. Casse, B.D.F.; Lu, W.T.; Huang, Y.J.; Gultepe, E.; Menon, L.; Sridhar, S. Super-resolution imaging using a three-dimensional metamaterials nanolens. Appl. Phys. Lett. 2010, 96, 023114. [CrossRef]

19. Boechler, N.; Theocharis, G.; Daraio, C. Bifurcation-based acoustic switching and rectification. Nat. Mater. 2011, 10, 665-668. [CrossRef] [PubMed]

20. Zhu, Y.; Fan, X.; Liang, B.; Cheng, J.; Jing, Y. Ultrathin Acoustic Metasurface-Based Schroeder Diffuser. Phys. Rev. X 2017, 7, 021034. [CrossRef]

21. Yang, Z.; Gao, F.; Shi, X.; Lin, X.; Gao, Z.; Chong, Y.; Zhang, B. Topological Acoustics. Phys. Rev. Lett. 2015, 114, 114301. [CrossRef] [PubMed]

22. Chen, Z.; Wu, Y. Tunable Topological Phononic Crystals. Phys. Rev. Appl. 2016, 5, 054021. [CrossRef]

23. Zhu, Y.; Peng, Y.; Fan, X.; Yang, J.; Liang, B.; Zhu, X.; Cheng, J. Experimental Realization of Acoustic Chern Insulator. arXiv 2018, arXiv:1801.07942.

24. Fleury, R.; Khanikaev, A.B.; Alù, A. Floquet topological insulators for sound. Nat. Commun. 2016, 7, 11744. [CrossRef] [PubMed]

25. Khanikaev, A.B.; Fleury, R.; Mousavi, S.H.; Alù, A. Topologically robust sound propagation in an angular-momentum-biased graphene-like resonator lattice. Nat. Commun. 2015, 6, 8260. [CrossRef] [PubMed]

26. Hillenbrand, R.; Taubner, T.; Keilmann, F. Phonon-enhanced light-matter interaction at the nanometre scale. Nature 2002, 418, 159-162. [CrossRef] [PubMed]

27. Lan, K.; Liu, J.; Li, Z.; Xie, X.; Huo, W.; Chen, Y.; Ren, G.; Zheng, C.; Yang, D.; Li, S. Progress in octahedral spherical hohlraum study. Matter Radiat. Extrem. 2016, 1, 8-27. [CrossRef]

28. Campbell, E.M.; Goncharov, V.N.; Sangster, T.C.; Regan, S.P.; Radha, P.B.; Betti, R.; Myatt, J.F.; Froula, D.H.; Rosenberg, M.J.; Igumenshchev, I.V. Laser-direct-drive program: Promise, challenge, and path forward. Matter Radiat. Extrem. 2017, 2, 37-54. [CrossRef]

29. Murakami, M.; Nishi, D. Optimization of laser illumination configuration for directly driven inertial confinement fusion. Matter Radiat. Extrem. 2016, 2, 55-68. [CrossRef]

30. Baranov, D.G.; Wersäll, M.; Cuadra, J.; Antosiewicz, T.J.; Shegai, T. Novel nanostructures and materials for strong light-matter interactions. ACS Photonics 2017, 5, 24-42. [CrossRef]

31. Zhang, F.; Feng, S.; Qiu, K.; Liu, Z.; Fan, Y.; Zhang, W.; Zhao, Q.; Zhou, J. Mechanically stretchable and tunable metamaterial absorber. Appl. Phys. Lett. 2015, 106, 091907. [CrossRef]

32. Fan, Y.; Shen, N.H.; Koschny, T.; Soukoulis, C.M. Tunable Terahertz Meta-Surface with Graphene Cut-Wires. ACS Photonics 2015, 2, 151-156. [CrossRef]

33. Fan, Y.; Shen, N.H.; Zhang, F.; Wei, Z.; Li, H.; Zhao, Q.; Fu, Q.; Zhang, P.; Koschny, T.; Soukoulis, C.M. Electrically Tunable Goos-Hänchen Effect with Graphene in the Terahertz Regime. Adv. Opt. Mater. 2016, 4, 1824-1828. [CrossRef]

34. Peng, R.; Xiao, Z.; Zhao, Q.; Zhang, F.; Meng, Y.; Li, B.; Zhou, J.; Fan, Y.; Zhang, P.; Shen, N.H. Temperature-Controlled Chameleonlike Cloak. Phys. Rev. X 2017, 7, 011033. [CrossRef]

35. Huang, Y.; Yao, Z.; Hu, F.; Liu, C.; Yu, L.; Jin, Y.; Xu, X. Tunable circular polarization conversion and asymmetric transmission of planar chiral graphene-metamaterial in terahertz region. Carbon 2017, 119, 305-313. [CrossRef]

36. Fu, Q.; Zhang, F.; Fan, Y.; Dong, J.; Cai, W.; Zhu, W.; Chen, S.; Yang, R. Weak coupling between bright and dark resonators with electrical tunability and analysis based on temporal coupled-mode theory. Appl. Phys. Lett. 2017, 110, 221905. [CrossRef]

37. Fan, Y.; Qiao, T.; Zhang, F.; Fu, Q.; Dong, J.; Kong, B.; Li, H. An electromagnetic modulator based on electrically controllable metamaterial analogue to electromagnetically induced transparency. Sci. Rep. 2017, 7, 40441. [CrossRef] [PubMed]

38. Fan, Y.; Tu, L.; Zhang, F.; Fu, Q.; Zhang, Z.; Wei, Z.; Li, H. Broadband Terahertz Absorption in Graphene-Embedded Photonic Crystals. Plasmonics 2017, 13, 1-6. [CrossRef] 
39. Fan, Y.; Shen, N.H.; Zhang, F.; Zhao, Q.; Wei, Z.; Zhang, P.; Dong, J.; Fu, Q.; Li, H.; Soukoulis, C.M. Photoexcited Graphene Metasurfaces: Significantly Enhanced and Tunable Magnetic Resonances. ACS Photonics 2018, 5, 1612-1618. [CrossRef]

40. Cao, T.; Mao, L.; Gao, D.; Ding, W.; Qiu, C.W. Fano resonant $\mathrm{Ge}_{2} \mathrm{Sb}_{2} \mathrm{Te}_{5}$ nanoparticles realize switchable lateral optical force. Nanoscale 2016, 8, 5657-5666. [CrossRef] [PubMed]

41. Hao, J.; Wang, J.; Liu, X.; Padilla, W.J.; Zhou, L.; Qiu, M. High performance optical absorber based on a plasmonic metamaterial. Appl. Phys. Lett. 2010, 96, 251104. [CrossRef]

42. Hao, J.; Zhou, L.; Qiu, M. Nearly total absorption of light and heat generation by plasmonic metamaterials. Phys. Rev. B Condens. Matter 2011, 83, 165107. [CrossRef]

43. Qiu, K.; Jia, N.; Liu, Z.; Wu, C.; Fan, Y.; Fu, Q.; Zhang, F.; Zhang, W. Electrically reconfigurable split ring resonator covered by nematic liquid crystal droplet. Opt. Express 2016, 24, 27096-27103. [CrossRef] [PubMed]

44. Fu, Q.; Zhang, F.; Fan, Y.; He, X.; Qiao, T.; Kong, B. Electrically tunable Fano-type resonance of an asymmetric metal wire pair. Opt. Express 2016, 24, 11708-11715. [CrossRef] [PubMed]

45. Fan, Y.; Liu, Z.; Zhang, F.; Zhao, Q.; Wei, Z.; Fu, Q.; Li, J.; Gu, C.; Li, H. Tunable mid-infrared coherent perfect absorption in a graphene meta-surface. Sci. Rep. 2015, 5, 13956. [CrossRef] [PubMed]

46. Fan, Y.; Zhang, F.; Zhao, Q.; Wei, Z.; Li, H. Tunable terahertz coherent perfect absorption in a monolayer graphene. Opt. Lett. 2014, 39, 6269-6272. [CrossRef] [PubMed]

47. Zhang, X.; Davanço, M.; Urzhumov, Y.; Shvets, G.; Forrest, S.R. From scattering parameters to Snell's law: A subwavelength near-infrared negative-index metamaterial. Phys. Rev. Lett. 2008, 101, 267401. [CrossRef] [PubMed]

48. Popa, B.I.; Cummer, S.A. Nonreciprocal active metamaterials. Phys. Rev. B 2012, 85, 205101. [CrossRef]

49. Fan, Y.C.; Zhang, F.L.; Shen, N.H.; Fu, Q.H.; Wei, Z.Y.; Li, H.Q.; Soukoulis, C.M. Achieving a high-Q response in metamaterials by manipulating the toroidal excitations. Phys. Rev. A 2018, 97, 033816. [CrossRef]

50. Li, J.; Chan, C.T. Double-negative acoustic metamaterial. Phys. Rev. E 2004, 70, 055602. [CrossRef] [PubMed]

51. Shen, H.J.; Wen, J.H.; Yu, D.L.; Cai, L.; Wen, X.S. Research on a cylindrical cloak with active acoustic metamaterial layers. Acta Phys. Sin. 2012, 61, 134303.

52. Chen, P.Y.; Farhat, M.; Guenneau, S.; Enoch, S.; Alu, A. Acoustic scattering cancellation via ultrathin pseudo-surface. Appl. Phys. Lett. 2011, 99, 191913. [CrossRef]

53. Zhao, J.; Li, B.; Chen, Z.; Qiu, C.W. Manipulating acoustic wavefront by inhomogeneous impedance and steerable extraordinary reflection. Sci. Rep. 2013, 3, 2537. [CrossRef] [PubMed]

54. Cummer, S.A.; Christensen, J.; Alù, A. Controlling sound with acoustic metamaterials. Nat. Rev. Mater. 2016, 1, 16001. [CrossRef]

55. Zhang, H.; Xiao, Y.; Wen, J.; Yu, D.; Wen, X. Ultra-thin smart acoustic metasurface for low-frequency sound insulation. Appl. Phys. Lett. 2016, 108, 141902. [CrossRef]

56. Yang, Z.; Dai, H.M.; Chan, N.H.; Ma, G.C.; Sheng, P. Acoustic metamaterial panels for sound attenuation in the 50-1000 Hz regime. Appl. Phys. Lett. 2010, 96, 041906. [CrossRef]

57. Akl, W.; Baz, A. Stability analysis of active acoustic metamaterial with programmable bulk modulus. Smart Mater. Struct. 2011, 20, 125010. [CrossRef]

58. Jin, Y.; Boudouti, E.H.E.; Pennec, Y.; Djafarirouhani, B. Tunable Fano resonances of Lamb modes in a pillared metasurface. J. Phys. D Appl. Phys. 2017, 50, 425304. [CrossRef]

59. Jin, Y.; Bonello, B.; Moiseyenko, R.P.; Yan, P.; Boyko, O.; Djafari-Rouhani, B. Pillar-type acoustic metasurface. Phys. Rev. B 2017, 96, 104311. [CrossRef]

60. Xie, B.; Tang, K.; Cheng, H.; Liu, Z.; Chen, S.; Tian, J. Coding Acoustic Metasurfaces. Adv. Mater. 2016, 29, 1603507. [CrossRef] [PubMed]

61. Akl, W.; Baz, A. Multicell Active Acoustic Metamaterial With Programmable Effective Densities. J. Dyn. Syst. Meas. Control 2012, 134, 061001. [CrossRef]

62. Yu, S.Y.; Ni, X.; Xu, Y.L.; He, C.; Nayar, P.; Lu, M.H.; Chen, Y.F. Extraordinary Acoustic Transmission in a Helmholtz Resonance Cavity-Constructed Acoustic Grating. Chin. Phys. Lett. 2016, 33, 044302. [CrossRef]

63. Liu, Z.; Zhang, X.; Mao, Y.; Zhu, Y.Y.; Yang, Z.; Chan, C.T.; Sheng, P. Locally resonant sonic materials. Science 2000, 289, 1734-1736. [CrossRef] [PubMed]

64. Fang, N.; Xi, D.; Xu, J.; Ambati, M.; Srituravanich, W.; Sun, C.; Zhang, X. Ultrasonic metamaterials with negative modulus. Nat. Mater. 2006, 5, 452-456. [CrossRef] [PubMed] 
65. Kushwaha, M.S.; Halevi, P.; Martinez, G.; Dobrzynski, L.; Djafari-Rouhani, B. Theory of acoustic band structure of periodic elastic composites. Phys. Rev. B 1994, 49, 2313. [CrossRef]

66. Kushwaha, M.S.; Halevi, P.; Dobrzynski, L.; Djafari-Rouhani, B. Acoustic band structure of periodic elastic composites. Phys. Rev. Lett. 1993, 71, 2022-2025. [CrossRef] [PubMed]

67. Lee, S.H.; Park, C.M.; Seo, Y.M.; Wang, Z.G.; Kim, C.K. Acoustic metamaterial with negative modulus. J. Phys. Condens. Matter 2009, 21, 175704. [CrossRef] [PubMed]

68. Zhang, S.; Yin, L.; Fang, N. Focusing ultrasound with an acoustic metamaterial network. Phys. Rev. Lett. 2009, 102, 194301. [CrossRef] [PubMed]

69. Zigoneanu, L.; Popa, B.I.; Cummer, S.A. Design and measurements of a broadband two-dimensional acoustic lens. Phys. Rev. B 2011, 84, 024305. [CrossRef]

70. Lee, S.H.; Park, C.M.; Seo, Y.M.; Kim, C.K. Reversed Doppler effect in double negative metamaterials. Phys. Rev. B 2010, 81, 241102. [CrossRef]

71. Liu, F.; Cai, F.; Peng, S.; Hao, R.; Ke, M.; Liu, Z. Parallel acoustic near-field microscope: A steel slab with a periodic array of slits. Phys. Rev. E 2009, 80, 026603. [CrossRef] [PubMed]

72. Zhu, J.; Christensen, J.; Jung, J.; Martinmoreno, L.; Yin, X.; Fok, L.; Zhang, X.; Garciavidal, F.J. A holey-structured metamaterial for acoustic deep-subwavelength imaging. Nat. Phys. 2010, 7, 52-55. [CrossRef]

73. Zhang, S.; Xia, C.; Fang, N. Broadband acoustic cloak for ultrasound waves. Phys. Rev. Lett. 2011, 106, 024301. [CrossRef] [PubMed]

74. Li, X.F.; Ni, X.; Feng, L.; Lu, M.H.; He, C.; Chen, Y.F. Tunable unidirectional sound propagation through a sonic-crystal-based acoustic diode. Phys. Rev. Lett. 2011, 106, 084301. [CrossRef] [PubMed]

75. Vasseur, J.O.; Deymier, P.A.; Chenni, B.; Djafari-Rouhani, B.; Dobrzynski, L.; Prevost, D. Experimental and theoretical evidence for the existence of absolute acoustic band gaps in two-dimensional solid phononic crystals. Phys. Rev. Lett. 2001, 86, 3012-3015. [CrossRef] [PubMed]

76. Pennec, Y.; Djafari-Rouhani, B.; Vasseur, J.O.; Khelif, A.; Deymier, P.A. Tunable filtering and demultiplexing in phononic crystals with hollow cylinders. Phys. Rev. E 2004, 69, 046608. [CrossRef] [PubMed]

77. Jin, Y.; Fernez, N.; Pennec, Y.; Bonello, B.; Moiseyenko, R.P.; Hémon, S.; Pan, Y.; Djafarirouhani, B. Tunable waveguide and cavity in a phononic crystal plate by controlling whispering-gallery modes in hollow pillars. Phys. Rev. B 2016, 93, 054109. [CrossRef]

78. Wu, Y.; Lai, Y.; Zhang, Z.Q. Effective medium theory for elastic metamaterials in two dimensions. Phys. Rev. $B$ 2007, 76, 205313. [CrossRef]

79. Oudich, M.; Djafari-Rouhani, B.; Pennec, Y.; Assouar, M.B.; Bonello, B. Negative effective mass density of acoustic metamaterial plate decorated with low frequency resonant pillars. J. Appl. Phys. 2014, 116, 184504. [CrossRef]

80. Mei, J.; Liu, Z.; Wen, W.; Sheng, P. Effective mass density of fluid-solid composites. Phys. Rev. Lett. 2006, 96, 024301. [CrossRef] [PubMed]

81. Liu, Z.; Chan, C.T.; Sheng, P. Analytic model of phononic crystals with local resonances. Phys. Rev. B 2005, 71, 014103. [CrossRef]

82. Milton, G.W.; Willis, J.R. On Modifications of Newton's Second Law and Linear Continuum Elastodynamics. Proc. R. Soc. A 2007, 463, 855-880. [CrossRef]

83. Yao, S.; Zhou, X.; Hu, G. Experimental study on negative effective mass in a 1D mass spring system. New J. Phys. 2008, 10, 043020. [CrossRef]

84. Akl, W.; Baz, A. Multi-cell active acoustic metamaterial with programmable bulk modulus. J. Intell. Mater. Syst. Struct. 2010, 21, 541-556. [CrossRef]

85. Lee, S.H.; Wright, O.B. Origin of Negative Density and Modulus in Acoustic Metamaterials. Physics 2015, 93, 024302. [CrossRef]

86. Brunet, T.; Leng, J.; Mondainmonval, O. Soft acoustic metamaterials. Science 2013, 342, 323-324. [CrossRef] [PubMed]

87. Mei, J.; Liu, Z.; Wen, W.; Sheng, P. Effective dynamic mass density of composites. Phys. Rev. B 2007, 76, 134205. [CrossRef]

88. Lee, S.H.; Park, C.M.; Seo, Y.M.; Wang, Z.G.; Kim, C.K. Composite acoustic medium with simultaneously negative density and modulus. Phys. Rev. Lett. 2010, 104, 054301. [CrossRef] [PubMed] 
89. Yong, M.S.; Park, J.J.; Lee, S.H.; Park, C.M.; Kim, C.K.; Lee, S.H. Acoustic metamaterial exhibiting four different sign combinations of density and modulus. J. Appl. Phys. 2012, 111, 023504.

90. Babaee, S.; Viard, N.; Wang, P.; Fang, N.X.; Bertoldi, K. Harnessing Deformation to Switch On and Off the Propagation of Sound. Adv. Mater. 2016, 28, 1631-1635. [CrossRef] [PubMed]

91. Tournat, V.; Pagneux, V.; Lafarge, D.; Jaouen, L. Multiple scattering of acoustic waves and porous absorbing media. Phys. Rev. E 2004, 70, 026609. [CrossRef] [PubMed]

92. Groby, J.P.; Lagarrigue, C.; Brouard, B.; Dazel, O.; Tournat, V.; Nennig, B. Using simple shape three-dimensional rigid inclusions to enhance porous layer absorption. J. Acoust. Soc. Am. 2014, 136, 1139. [CrossRef] [PubMed]

93. Leroy, V.; Bretagne, A.; Fink, M.; Willaime, H.; Tabeling, P.; Tourin, A. Design and characterization of bubble phononic crystals. Appl. Phys. Lett. 2009, 95, 171904. [CrossRef]

94. Li, Y.; Assouar, B.M. Acoustic metasurface-based perfect absorber with deep subwavelength thickness. Appl. Phys. Lett. 2016, 108, 063502. [CrossRef]

95. Lagarrigue, C.; Groby, J.P.; Tournat, V.; Dazel, O.; Umnova, O. Absorption of sound by porous layers with embedded periodic arrays of resonant inclusions. J. Acoust. Soc. Am. 2013, 134, 4670. [CrossRef] [PubMed]

96. Leroy, V.; Strybulevych, A.; Lanoy, M.; Lemoult, F.; Tourin, A.; Page, J.H. Superabsorption of acoustic waves with bubble metascreens. Phys. Rev. B 2015, 91, 020301. [CrossRef]

97. Lee, S.H.; Park, C.M.; Yong, M.S.; Zhi, G.W.; Kim, C.K. Acoustic metamaterial with negative density. Phys. Lett. A 2009, 373, 4464-4469. [CrossRef]

98. Ivansson, S.M. Sound absorption by viscoelastic coatings with periodically distributed cavities. J. Acoust. Soc. Am. 2006, 119, 3558-3567. [CrossRef]

99. Ivansson, S.M. Numerical design of Alberich anechoic coatings with superellipsoidal cavities of mixed sizes. J. Acoust. Soc. Am. 2008, 124, 1974. [CrossRef] [PubMed]

100. Sharma, G.S.; Skvortsov, A.; MacGillivray, I.; Kessissoglou, N. Sound transmission through a periodically voided soft elastic medium submerged in water. Wave Motion 2017, 70, 101-112. [CrossRef]

101. Lai, Y.; Wu, Y.; Sheng, P.; Zhang, Z.Q. Hybrid elastic solids. Nat. Mater. 2011, 10, 620-624. [CrossRef] [PubMed]

102. Sharma, G.S.; Skvortsov, A.; Macgillivray, I.; Kessissoglou, N. Acoustic performance of gratings of cylindrical voids in a soft elastic medium with a steel backing. J. Acoust. Soc. Am. 2017, 141, 4694. [CrossRef] [PubMed]

103. Shen, H.; Wen, J.; Païdoussis, M.P.; Yu, D.; Cai, L.; Wen, X. Parameter derivation for an acoustic cloak based on scattering theory and realization with tunable metamaterials. Model. Simul. Mater. Sci. Eng. 2013, 21, 065011. [CrossRef]

104. Park, J.J.; Park, C.M.; Lee, K.J.B.; Lee, S.H. Acoustic superlens using membrane-based metamaterials. Appl. Phys. Lett. 2015, 106, 051901. [CrossRef]

105. Zhu, R.; Ma, C.; Zheng, B.; Musa, M.Y.; Jing, L.; Yang, Y.; Wang, H.; Dehdashti, S.; Fang, N.X.; Chen, H. Bifunctional acoustic metamaterial lens designed with coordinate transformation. Appl. Phys. Lett. 2017, 110, 113503. [CrossRef]

106. Jing, Y.; Xu, J.; Fang, N.X. Numerical study of a near-zero-index acoustic metamaterial. Phys. Lett. A 2012, 376, 2834-2837. [CrossRef]

107. Baz, A. The structure of an active acoustic metamaterial with tunable effective density. New J. Phys. 2009, 11, 123010. [CrossRef]

108. Popa, B.I.; Cummer, S.A. Non-reciprocal and highly nonlinear active acoustic metamaterials. Nat. Commun. 2014, 5, 3398. [CrossRef] [PubMed]

109. Bishop, K.J. Acoustic metamaterials: Living bandgaps. Nat. Mater. 2017, 16, 786-787. [CrossRef] [PubMed]

110. Zhang, C.; Hu, X. Three-Dimensional Single-Port Labyrinthine Acoustic Metamaterial: Perfect Absorption with Large Bandwidth and Tunability. Phys. Rev. Appl. 2016, 6, 064025. [CrossRef]

111. Fleury, R.; Sounas, D.L.; Alù, A. Subwavelength ultrasonic circulator based on spatiotemporal modulation. Phys. Rev. B 2015, 91, 174306. [CrossRef]

112. Oudich, M.; Li, Y. Tunable sub-wavelength acoustic energy harvesting with a metamaterial plate. J. Phys. D Appl. Phys. 2017, 50, 315104. [CrossRef]

113. Lissek, H.; Boulandet, R.; Fleury, R. Electroacoustic absorbers: Bridging the gap between shunt loudspeakers and active sound absorption. J. Acoust. Soc. Am. 2011, 129, 2968-2978. [CrossRef] [PubMed] 
114. Casadei, F.; Delpero, T.; Bergamini, A.; Ermanni, P. Piezoelectric resonator arrays for tunable acoustic waveguides and metamaterials. J. Appl. Phys. 2012, 112, 064902. [CrossRef]

115. Sheng-Bing, C.; Hong, W.J.; Gang, W.; Sen, W.X. Tunable band gaps in acoustic metamaterials with periodic arrays of resonant shunted piezos. Chin. Phys. B 2013, 22, 074301.

116. Allam, A.; Elsabbagh, A.; Akl, W. Modeling and design of two-dimensional membrane-type active acoustic metamaterials with tunable anisotropic density. J. Acoust. Soc. Am. 2016, 140, 3607-3618. [CrossRef] [PubMed]

117. Li, Z.; Yang, D.; Liu, S.; Yu, S.; Lu, M.; Zhu, J.; Zhang, S.; Zhu, M.; Guo, X.; Wu, H. Broadband gradient impedance matching using an acoustic metamaterial for ultrasonic transducers. Sci. Rep. 2017, 7, 42863. [CrossRef] [PubMed]

118. Airoldi, L.; Ruzzene, M. Design of tunable acoustic metamaterials through periodic arrays of resonant shunted piezos. New J. Phys. 2011, 13, 113010. [CrossRef]

119. Sugino, C.; Leadenham, S.; Ruzzene, M.; Erturk, A. An investigation of electroelastic bandgap formation in locally resonant piezoelectric metastructures. Smart Mater. Struct. 2017, 26, 055029. [CrossRef]

120. Casadei, F.; Ruzzene, M.; Dozio, L.; Cunefare, K.A. Broadband vibration control through periodic arrays of resonant shunts: Experimental investigation on plates. Smart Mater. Struct. 2010, 19, 015002. [CrossRef]

121. Akl, W.; Baz, A. Experimental characterization of active acoustic metamaterial cell with controllable dynamic density. J. Appl. Phys. 2012, 112, 084912. [CrossRef]

122. Akl, W.; Baz, A. Analysis and experimental demonstration of an active acoustic metamaterial cell. J. Appl. Phys. 2012, 111, 044505. [CrossRef]

123. Akl, W.; Baz, A. Active Acoustic Metamaterial With Simultaneously Programmable Density and Bulk Modulus. J. Vib. Acoust. 2013, 135, 031001. [CrossRef]

124. Allam, A.; Elsabbagh, A.; Akl, W. Experimental demonstration of one-dimensional active plate-type acoustic metamaterial with adaptive programmable density. J. Appl. Phys. 2017, 121, 125106. [CrossRef]

125. Ma, G.; Yang, M.; Yang, Z.; Sheng, P. Low-frequency narrow-band acoustic filter with large orifice. Appl. Phys. Lett. 2013, 103, 011903. [CrossRef]

126. Popa, B.I.; Zigoneanu, L.; Cummer, S.A. Tunable active acoustic metamaterials. Phys. Rev. B 2013, 88, 024303. [CrossRef]

127. Jin, Y.; Bonello, B.; Pan, Y. Acoustic metamaterials with piezoelectric resonant structures. J. Phys. D Appl. Phys. 2014, 47, 245301. [CrossRef]

128. Liang, Z.; Willatzen, M.; Li, J.; Christensen, J. Tunable acoustic double negativity metamaterial. Sci. Rep. 2012, 2, 859. [CrossRef] [PubMed]

129. Graciásalgado, R.; Torrent, D; Sánchezdehesa, J. Double-negative acoustic metamaterials based on quasi-two-dimensional fluid-like shells. New J. Phys. 2012, 14, 103052. [CrossRef]

130. Lee, K.J.B.; Jung, M.K.; Lee, S.H. Highly tunable acoustic metamaterials based on a resonant tubular array. Phys. Rev. B Condens. Matter 2012, 86, 184302. [CrossRef]

131. Popa, B.I.; Shinde, D.; Konneker, A.; Cummer, S.A. Active acoustic metamaterials reconfigurable in real-time. Phys. Rev. B 2015, 91, 220303. [CrossRef]

132. Lan, J.; Li, Y.; Yu, H.; Li, B.; Liu, X. Nonlinear effects in acoustic metamaterial based on a cylindrical pipe with ordered Helmholtz resonators. Phys. Lett. A 2017, 381, 1111-1117. [CrossRef]

133. Achilleos, V.; Theocharis, G.; Richoux, O.; Pagneux, V. Non-Hermitian acoustic metamaterials: Role of exceptional points in sound absorption. Phys. Rev. B 2017, 95, 144303. [CrossRef]

134. Fleury, R.; Alù, A. Extraordinary sound transmission through density-near-zero ultranarrow channels. Phys. Rev. Lett. 2013, 111, 055501. [CrossRef] [PubMed]

135. Ma, G.; Yang, M.; Xiao, S.; Yang, Z.; Sheng, P. Acoustic metasurface with hybrid resonances. Nat. Mater. 2014, 13, 873-878. [CrossRef] [PubMed]

136. Yang, Z.; Mei, J.; Yang, M.; Chan, N.H.; Sheng, P. Membrane-type acoustic metamaterial with negative dynamic mass. Phys. Rev. Lett. 2008, 101, 204301. [CrossRef] [PubMed]

137. Langfeldt, F.; Riecken, J.; Gleine, W.; Estorff, O.V. A membrane-type acoustic metamaterial with adjustable acoustic properties. J. Sound Vib. 2016, 373, 1-18. [CrossRef]

138. Zhang, J.; Romero-García, V.; Theocharis, G.; Richoux, O.; Achilleos, V.; Frantzeskakis, D.J. Bright and gap solitons in membrane-type acoustic metamaterials. Phys. Rev. E 2017, 96, 022214. [CrossRef] [PubMed] 
139. Langfeldt, F.; Kemsies, H.; Gleine, W.; von Estorff, O. Perforated membrane-type acoustic metamaterials. Phys. Lett. A 2017, 381, 1457-1462. [CrossRef]

140. Naify, C.J.; Chang, C.M.; Mcknight, G.; Nutt, S. Transmission loss and dynamic response of membrane-type locally resonant acoustic metamaterials. J. Appl. Phys. 2010, 108, 114905. [CrossRef]

141. Xiao, S.; Ma, G.; Li, Y.; Yang, Z.; Sheng, P. Active control of membrane-type acoustic metamaterial by electric field. Appl. Phys. Lett. 2015, 106, 091904. [CrossRef]

142. Zhang, Y.; Wen, J.; Xiao, Y.; Wen, X.; Wang, J. Theoretical investigation of the sound attenuation of membrane-type acoustic metamaterials. Phys. Lett. A 2012, 376, 1489-1494. [CrossRef]

143. Mei, J.; Ma, G.; Yang, M.; Yang, Z.; Wen, W.; Sheng, P. Dark acoustic metamaterials as super absorbers for low-frequency sound. Nat. Commun. 2012, 3, 756. [CrossRef] [PubMed]

144. Wang, P.; Casadei, F.; Shan, S.; Weaver, J.C.; Bertoldi, K. Harnessing buckling to design tunable locally resonant acoustic metamaterials. Phys. Rev. Lett. 2014, 113, 014301. [CrossRef] [PubMed]

145. Ma, G.; Fan, X.; Sheng, P.; Fink, M. Shaping reverberating sound fields with an actively tunable metasurface. Proc. Natl. Acad. Sci. USA 2018, 115, 6638-6643. [CrossRef] [PubMed]

146. Chen, Z.; Xue, C.; Fan, L.; Zhang, S.Y.; Li, X.J.; Zhang, H.; Ding, J. A tunable acoustic metamaterial with double-negativity driven by electromagnets. Sci. Rep. 2016, 6, 30254. [CrossRef] [PubMed]

147. Borcea, L.; Bruno, O. On the magneto-elastic properties of elastomer-ferromagnet composites. J. Mech. Phys. Solids 2001, 49, 2877-2919. [CrossRef]

148. Chen, X.; Xu, X.; Ai, S.; Chen, H.S.; Pei, Y.; Zhou, X. Active acoustic metamaterials with tunable effective mass density by gradient magnetic fields. Appl. Phys. Lett. 2014, 105, 071913. [CrossRef]

149. Zhao, J.; Li, X.; Wang, Y.; Wang, W.; Zhang, B.; Gai, X. Membrane acoustic metamaterial absorbers with magnetic negative stiffness. J. Acoust. Soc. Am. 2017, 141, 840-846. [CrossRef] [PubMed]

150. Jin, Y.; Yan, P.; Pan, Y.; Djafari-Rouhani, B. Phononic Crystal Plate with Hollow Pillars Actively Controlled by Fluid Filling. Crystals 2016, 6, 64. [CrossRef]

151. Jin, Y.; Pennec, Y.; Pan, Y.; Djafarirouhani, B. Phononic crystal plate with hollow pillars connected by thin bars. J. Phys. D Appl. Phys. 2017, 50, 035301. [CrossRef]

152. Xia, B.; Chen, N.; Xie, L.; Qin, Y.; Yu, D. Temperature-controlled tunable acoustic metamaterial with active band gap and negative bulk modulus. Appl. Acoust. 2016, 112, 1-9. [CrossRef]

153. Li, Y.; Shen, C.; Xie, Y.; Li, J.; Wang, W.; Cummer, S.A.; Jing, Y. Tunable asymmetric transmission via lossy acoustic metasurfaces. Phys. Rev. Lett. 2017, 119, 035501. [CrossRef] [PubMed]

154. Xie, B.; Cheng, H.; Tang, K.; Liu, Z.; Chen, S.; Tian, J. Multiband Asymmetric Transmission of Airborne Sound by Coded Metasurfaces. Phys. Rev. A 2017, 7, 024010. [CrossRef]

155. Li, Y.; Qi, S.; Assouar, M.B. Theory of metascreen-based acoustic passive phased array. New J. Phys. 2016, 18, 043024. [CrossRef]

(C) 2018 by the authors. Licensee MDPI, Basel, Switzerland. This article is an open access article distributed under the terms and conditions of the Creative Commons Attribution (CC BY) license (http://creativecommons.org/licenses/by/4.0/). 